\title{
Experimental Investigation into the Control and Load Alleviation Capabilities of Articulated Winglets
}

\author{
A. Gatto, ${ }^{1}$ P. Bourdin, ${ }^{2}$ and M. I. Friswell ${ }^{3}$ \\ ${ }^{1}$ Department of Mechanical Engineering, Brunel University, Uxbridge, Middlesex UB8 3PH, UK \\ ${ }^{2}$ Bombardier Aerospace, Core Engineering, Toronto, ON, Canada M3K 1 Y5 \\ ${ }^{3}$ College of Engineering, Swansea University, Swansea SA2 8PP, UK
}

Correspondence should be addressed to A. Gatto, alvin.gatto@brunel.ac.uk

Received 10 May 2012; Revised 6 August 2012; Accepted 6 August 2012

Academic Editor: N. Ananthkrishnan

Copyright ( 2012 A. Gatto et al. This is an open access article distributed under the Creative Commons Attribution License, which permits unrestricted use, distribution, and reproduction in any medium, provided the original work is properly cited.

\begin{abstract}
An experimental investigation into the real-time flow and control characteristics of a flying wing with articulated winglets is described in this paper. The philosophy of the concept centres around the use of active, in-flight adjustment of each wing's winglet dihedral angle, both as a primary means of aircraft roll control (single winglet actuation) and though smaller equal and simultaneous winglet deflections, tailor and alleviate main wing load. Results presented in this paper do provide good evidence of the concept's ability to adequately perform both tasks, although for the current chosen wing/winglet configuration, roll control authority was unable to achieve, per unit of control surface deflection, the same level of performance set by modern aileron-based roll control methodologies.
\end{abstract}

\section{Introduction}

For the majority of the last century, the primary means for aircraft control though the use of elevators for pitch control, ailerons for roll control, and a rudder for yaw control has remained largely unchallenged. For aircraft designers around the world, this control methodology represents the most reliable, robust, generally applicable, and effective means of aircraft attitude control that currently exists. While it is certainly true that this method of aircraft control has become much more complex as the rapid advance in aerospace technologies continues to accelerate [1], a wide-ranging successor to this traditional method, that can significantly improve upon this baseline method, giving substantial improvements in efficiency and performance, continues to remain operationally complex and/or difficult to justify.

While this required and necessary search remains ongoing, in large part to meet the ever-increasing demands on future aircraft operational effectiveness and environmental impact, the use of this traditional method of aircraft control does rely on the deflection of hinged, discrete control surfaces, which can, even under moderate levels of deflection, set up localised areas of severe adverse pressure gradient (typically along the hinge line) that both promote and produce regions of flow separation. Under these conditions, both control surface and overall wing efficiency is reduced leading to suboptimal aircraft performance. This drawback of the current system is one of the main reasons the search for "morphing" aircraft systems and technologies continues [213]. If successful, and through using control configurations that allow more general and subtle changes in streamwise curvature, morphing for control may lead to increases in aerodynamic efficiency while maintaining comparable performance. Unfortunately, however, the widespread use of modern morphing aircraft control systems remains largely unrealised since a rigorous cost/benefit analysis has not demonstrated a significant improvement upon current aircraft axis control methodologies.

Together with using traditional control surfaces for direct aircraft axis control, more and more studies of late have considered using smaller, more microscopic deflections of these control surfaces in flight to increase the performance and efficiency of aircraft over more of the mission profile. Recent work has detailed investigations into the use of simultaneous deflection of flaps, spoilers, and/or ailerons $[4,8$, $14,15]$ to adjust streamwise curvature to aid performance 


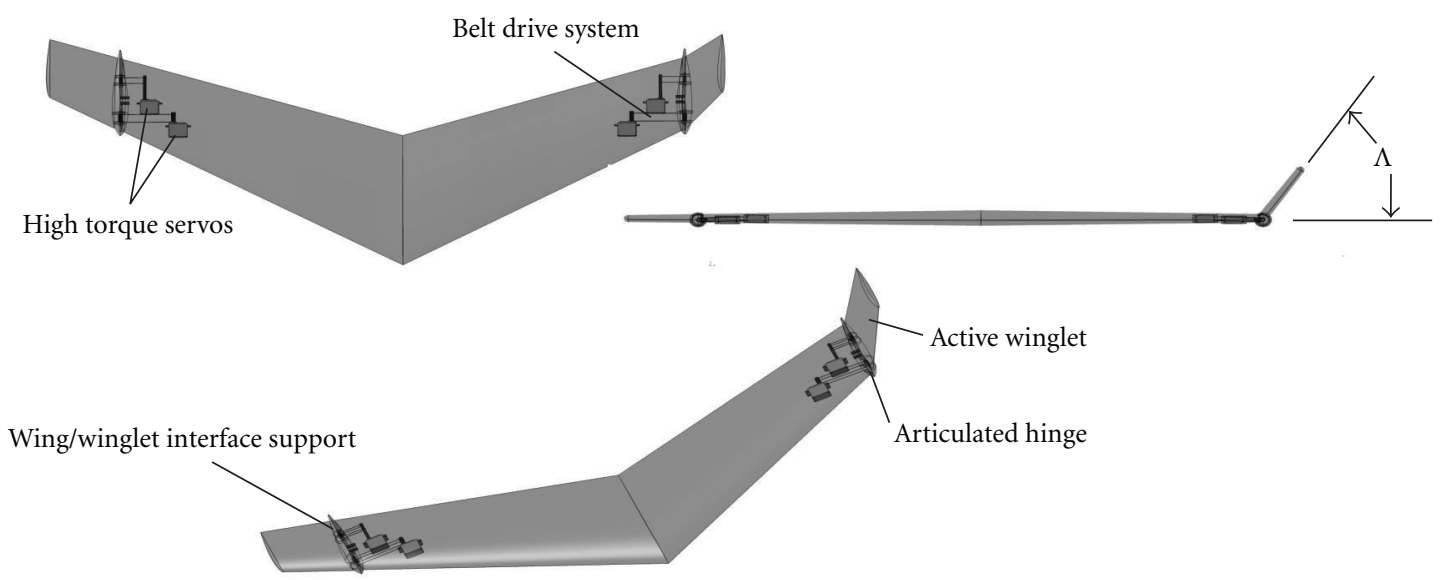

FIGURE 1: General schematic of the baseline flying wing with active winglets.

enhancement, with the general consensus being that benefits are probable. Of the benefits possible, manoeuvre load alleviation, spanwise and chordwise lift distribution optimisation (for minimum drag) as aircraft weight varies during flight as well as the placation of in-flight turbulence appear to be the most promising.

In this paper, work is presented that extends a concept for a novel aircraft roll control system considered in an earlier paper by the authors [16]. Together with investigating in more depth the dynamics of this control methodology as a substitute for tradition aileron control systems, the ability of the system to be used as a means of real-time wing load alleviation during flight is also considered. The experimental model tested, analysed, and evaluated used two actively controlled wingtips (one mounted at each wingtip) that were free to rotate about the wing-tip chord axis line. The model was also purpose built to allow for multiple dynamic surface pressure measurement on one upper wing surface as well as mounted on a six-component force and moment balance to measure, under test conditions, the real-time aerodynamic and control loads during winglet actuation.

\section{Experimental Setup and Apparatus}

2.1. The Flying Wing Model. A schematic of the swept wing model designed and built for the test programme is shown in Figure 1. The baseline configuration (without winglets) used a Zagi 12 wing section, 30 deg leading edge sweep, a wingspan of $1.2 \mathrm{~m}$ ( $1.54 \mathrm{~m}$ with winglets planar), zero washout, and root and tip chords of $0.326 \mathrm{~m}$ and $0.185 \mathrm{~m}$, respectively. All sections of the complete wing (comprising the main baseline wing sections and the winglets) were made of a blue foam core that was reinforced and strengthened with a bonded carbon and lacquered skin to further resist aerodynamic loading and produce an aerodynamically robust surface finish. To build the flying wing configuration, the two mirrored baseline semispan wing sections were mated and glued together at the root using additional carbon stiffening rods for extra strength. Prior to assembly, and to allow for the integration of the active wing-tip actuator assembly and the array of dynamic pressure transducers, sections of the under-surface of each baseline wing semispan section at the wing tip were removed. Internal portions of the blue foam core within the starboard (looking from behind the model) baseline semispan wing and winglet were also removed to accommodate integration of dynamic surface pressure transducer array.

Fifty-seven, 1 psi gage, dynamic pressure sensors with identical, custom-built amplifier electronics were used to measure the dynamic surface pressures on both the starboard baseline semiwing span and winglet combination. All pressure sensors used to instrument the model were high grade, commercial, dynamic pressure sensors, with a spatial footprint of less than $20 \times 10 \times 5 \mathrm{~mm}^{3}$ (including customised electronics). This small footprint allowed the successful integration of the pressure sensors in regions of interest close to the wing/winglet juncture as well as near the trailing edge of both the baseline wing and winglet. The chosen placement of the pressure transducers is shown in Figure 2. Initially, each pressure transducer was fixed in these positions with the exposed portion of the main active pressure port protruding out of the upper wing surface, exposing it to the main wing surface flow. To ensure that there was no undue aerodynamic contamination, each of these exposed sections was trimmed and sanded back to the main wing surface creating an aerodynamically smooth surface finish. Signal lines from all installed pressure transducers were channelled through the main wing section, exiting at the root spanwise station, and down the purposely designed and build wind tunnel support sting. For the active winglet, the control lines for the installed pressure transducers were carefully channelled through the wing/winglet interface support (Figure 1), ensuring that the winglet maintained a free and unhindered ability to rotate about its axis. This interface support (body of revolution) was manufactured and installed to facilitate seam-less and aerodynamically efficient rotation of the winglet around the baseline wing plane.

Together with the surface pressure transducers, seven dynamic pressure sensors identical to those used to obtain wing surface information were also installed at strategic 


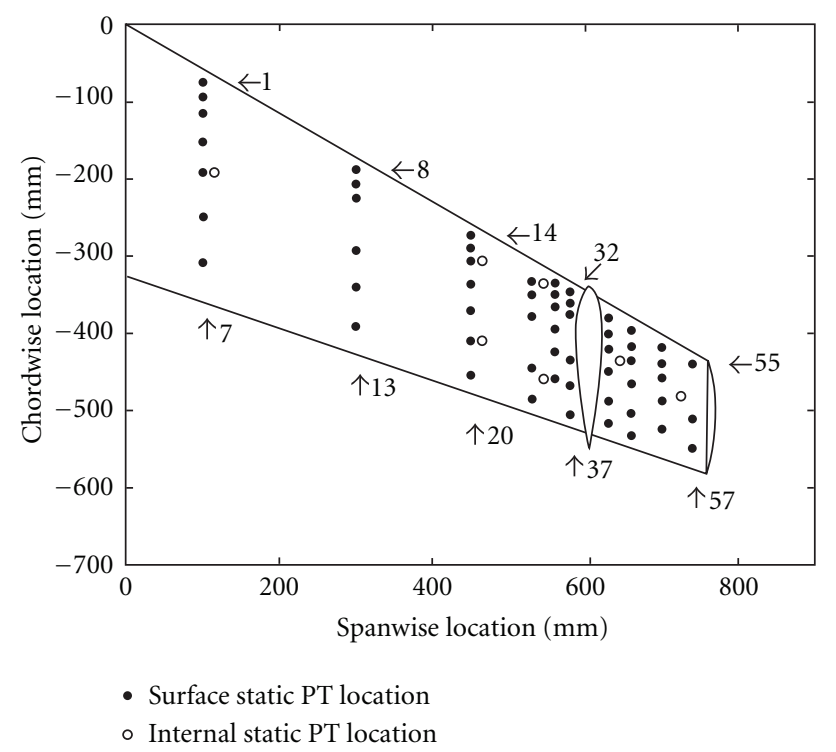

FIgURE 2: Position of surface and internal pressure transducer locations within the wing/winglet model.

locations throughout the starboard wing and winglet internal cavities (internal pressure sensors locations indicated also in Figure 2) to measure the internal cavity pressures during test conditions. Installation of these internal sensors together with the surface pressure transducers was carefully controlled and managed with all exposed main access wing/winglet covers and gaps surrounding the sensors sealed from exposure to the outside flowfield. One active port of all these installed internal pressure sensors was connected to a single pneumatic plastic tube (via several off-shoot branches) allowing a common reference for measurement and/or correction of internal static pressures offsets, if necessary, in the surface pressure results obtained. The other end of this tube, which was fed out of the model (at the wing root) and test section of the wing tunnel, was left exposed to static atmospheric conditions within the laboratory environment.

Initial testing of the pressure sensor/amplifier combination showed a measured combined nonlinearity and hysteresis of $\pm 0.25 \%$ and a useable frequency response up to $5 \mathrm{kHz}$. Additionally, the calibration of each pressure sensor was checked in situ against a Digitron 2081P pressure meter using a purposely designed pressure testing rig. For the surface pressure transducers, this rig allowed an airtight seal to be established over each sensor at each measurement station. After calibration, all pressure sensors (both surface and internal) were found to lie within a $95 \%$ confidence interval of $\pm 3 \%$.

To achieve winglet rotation, two digital Hitec HSR5995TG robot servos located at each wing tip were built into the baseline wingtip assembly. Both sets of servos were retrofitted with a belt drive system operating with a $1: 1$ gear ratio to rotate the winglets through a connected shaft within the wing/winglet interface support (Figure 1). The actuation torque produced by the servos was transferred from this shaft to the articulated winglet through four mounting struts that were all screwed and glued to a support frame within the active winglet. To ensure that both servos for each active winglet worked in unison, the signal lines from each servo were connected together allowing a single control signal to operate both servos.

2.2. The Wind Tunnel Measurement Environment. The experimental setup for the baseline swept wing/winglet combination is shown in Figure 3. The model was installed at midtest-section height inside a closed test section (height = $1.5 \mathrm{~m}$, width $=2.1 \mathrm{~m}$ ), closed circuit wind tunnel with a maximum operating freestream velocity of $60 \mathrm{~ms}^{-1} \pm 1 \mathrm{~ms}^{-1}$. The nominal flow speeds under test conditions were selected to lie between $30 \mathrm{~ms}^{-1} \leq V_{\infty} \leq 50 \mathrm{~ms}^{-1}$, giving a Reynolds number range based on the mean aerodynamic chord of the baseline configuration of $5.53 \times 10^{5} \leq \operatorname{Re}_{n} \leq 8.97 \times$ $10^{5}$. At the model station, the freestream turbulence level was approximately $0.2 \%$ with all six forces and moments transmitted from the model through a specifically designed support strut (mounted at the wing root quarter-chord position) to a force and moment balance located under the floor of the wind tunnel. Prior to the installation of the model, and at the start of every subsequent test, zero readings were obtained from this balance both before and after each test so that these tare and zero effects could be accounted for in the final results. No wind tunnel blockage corrections or artificial transition fixing on the model were applied throughout the entire test programme.

All four servos used to control and actuate the winglet were driven by a dSpace control system. This system was configured to generate pulse width modulated input signals, at $50 \mathrm{~Hz}$, with variable duty cycles corresponding to a pulse width range of between $400-2100 \mu$ s. Calibration of winglet dihedral angular position was carried out using a digital inclinometer (error $\pm 0.1 \%$ ) positioned on the 


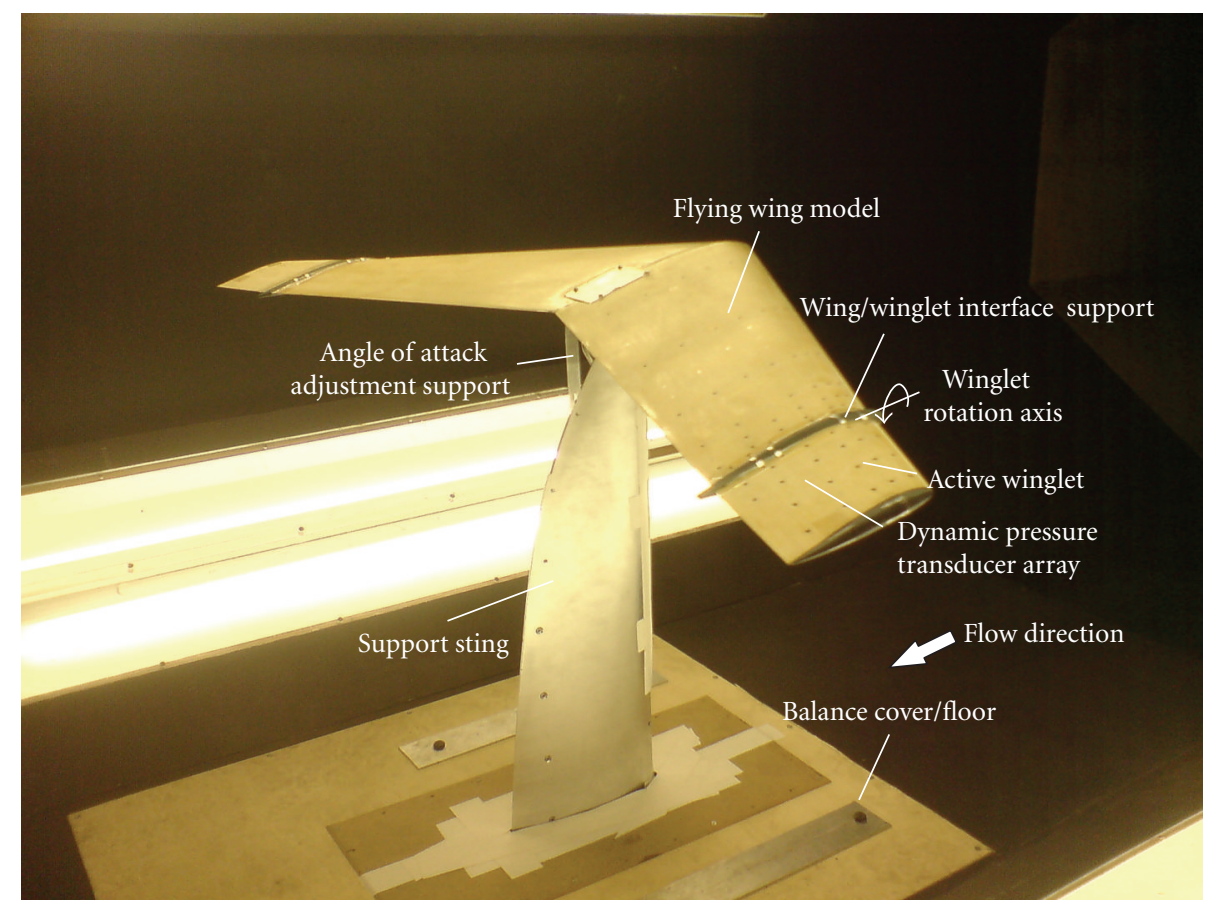

FIgURE 3: Experimental setup for active wing-tip flying wing.

control surfaces and matched to a readout from the dSpace control system indicating the input signal pulse width. Under no-wind conditions, the demanded input was found to be achieved within an error range of \pm 2 deg with a maximum achievable dihedral angle deflection for the active winglets being $\pm 75 \mathrm{deg}$ (positive dihedral-winglet rotation above the wing plane). The same digital inclinometer was used to calibrate the angle of attack of the model which was fixed within the range of $0-12 \mathrm{deg}$ (position error $\pm 1 \mathrm{deg}$ ) in increments of $4 \mathrm{deg}$.

The force and moment balance used to measure the response of the swept wing test rig to aerodynamic loading was an AMTI OR6-7-2000. This balance was fixed to the underside of the test section floor using a support frame allowing a model support sting (Figure 3) to be mounted to the active balance plate positioned just below the wind tunnel floor. A wooden cut-out balance cover was then used to cover the exposed cavity taking particular attention to ensure that no portion of this cover made contact with the support sting. The maximum lift, drag, and side force capabilities of this cell were rated at $\pm 8.9 \mathrm{kN}, \pm 4.45 \mathrm{kN}$, and $\pm 4.45 \mathrm{kN}$ with pitching, rolling, and yawing moment limits specified at $\pm 2.3 \mathrm{kNm}, \pm 2.3 \mathrm{kNm}$, and $\pm 1.1 \mathrm{kNm}$, respectively. After calibration, maximum errors for all six components returned prior to the wind tunnel testing was less than $\pm 2.5 \%$. Assessment of the maximum observed nonlinearity as well as zero drift after a pretesting programme were found to be better than $\pm 0.5 \%$. All data obtained from the load cell was digitised through the 16-bit dSpace data acquisition and control system, at $1000 \mathrm{~Hz}$, over a period of 30-60 s depending on the test configuration.

\section{Results and Discussion}

3.1. The Internal Static Pressure Field. As mentioned in Section 2, substantial effort during model assembly ensured that the internal cavities of the both the wing and winglet were sufficiently sealed from the outside flowfield to ensure no undue contamination. Leakage or exposure of the surface pressure field to the internal static pressure field may cause undue static and dynamic offsets in surface pressure magnitude, producing erroneous results. Tests conducted prior and during testing at conditions encompassing the entire Reynolds number range showed differences in registered internal cavity static pressures within both the wing and winglet cavities of less than $\pm 3 \%$. A similar analysis, evaluating the influence of winglet operation on the internal pressure field, was also found to lie within this error margin of less than $\pm 3 \%$.

3.2. Static Forces and Moments. The static forces and moments produced from single deflection of the starboard winglet through the range of $-75 \leq \Lambda \leq 75 \mathrm{deg}$ are shown in Figures 4 and 5 . The change in forces and moments from the baseline condition $(\Lambda=0 \mathrm{deg})$ for some dihedral angles is significant. The deflection of the winglet both above and below the wing plane produces an overall reduction in lift in agreement with [16]. Results from winglet deflections of $\Lambda= \pm 75$ deg on the lift coefficient in this study were found to produce lift reductions of approximately $\Delta C_{L}=-0.045$ (4.6\% for $\Lambda=-75 \mathrm{deg}$ ) and $\Delta C_{L}=-0.03$ (3\% for $\Lambda=$ $75 \mathrm{deg})$, respectively, $\left(\alpha=12 \mathrm{deg}\right.$ ) reducing to $\Delta C_{L}=-0.027$ and $\Delta C_{L}=-0.021$ at $\alpha=4 \mathrm{deg}$. Although the general trend 


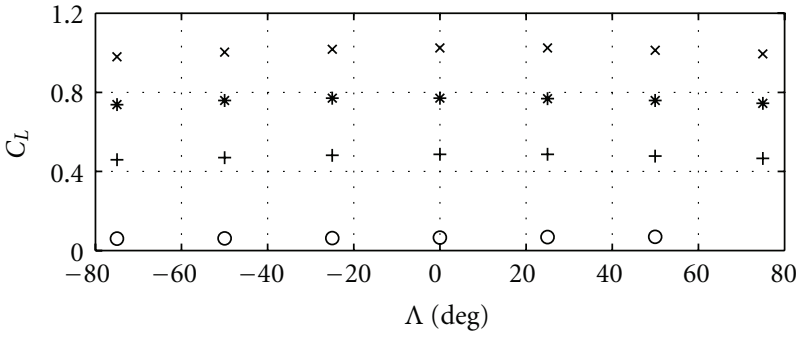

(a)

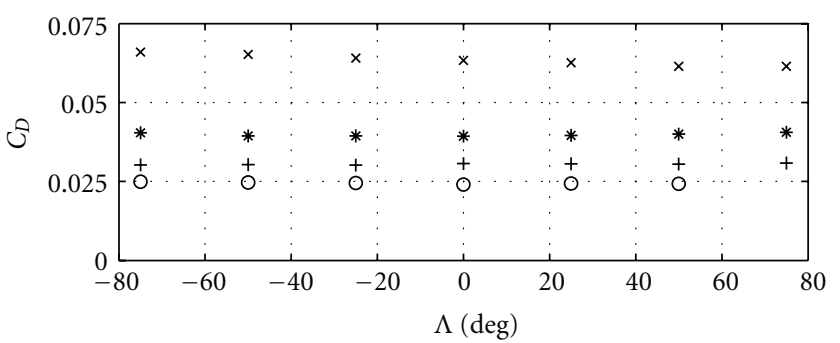

(c)

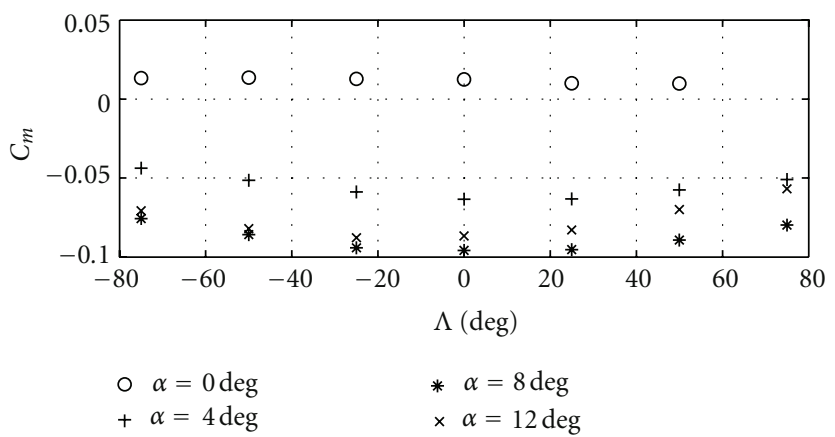

(e)

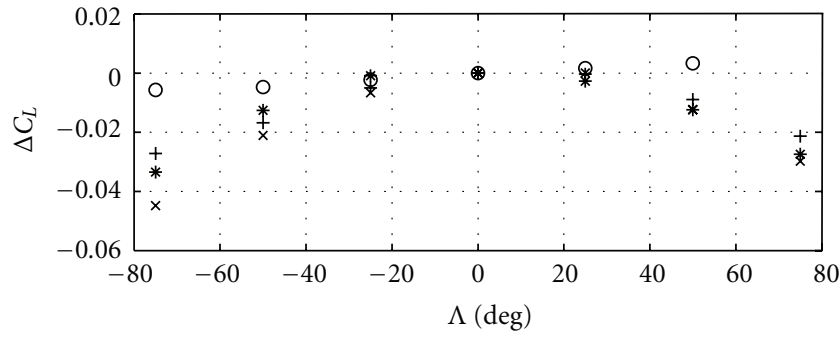

(b)

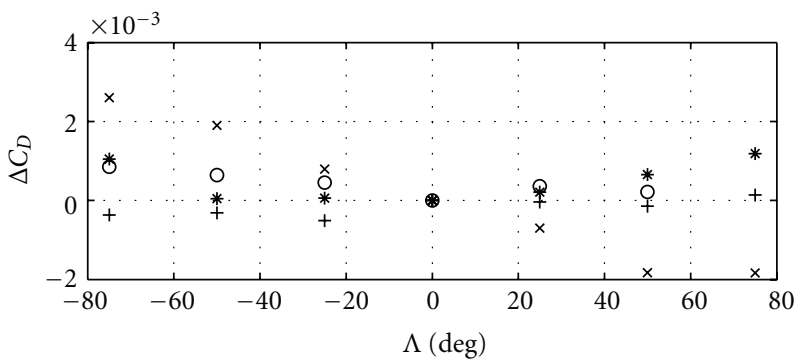

(d)

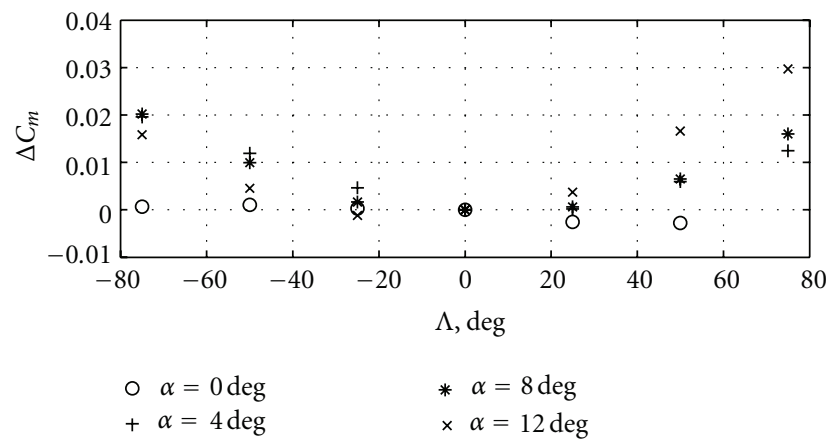

(f)

FIGURE 4: Effect of changing winglet dihedral angle on the longitudinal static forces and moments, $\operatorname{Re}_{n}=5.53 \times 10^{5}$.

in the reduction in lift is approximately symmetric with respect to the wing plane, there is a tendency for lift reduction to favour negative winglet deflections. The likely cause is a combination of the enhanced capabilities for $\Lambda>0 \mathrm{deg}$ to confine and maintain upper surface low pressure magnitudes as well as the influence of the nonsymmetric airfoil section chosen.

Considering the same operational conditions discussed for the results of lift coefficient above, results for drag coefficient are also shown in Figure 4. Overall, results for $\Delta C_{D}$ suggest almost no effect (within uncertainty) for $\alpha=0 \mathrm{deg}$ and $\alpha=4$ deg up to a maximum increase of 26 drag counts for $\Lambda=-75 \mathrm{deg}$ and $\alpha=12 \mathrm{deg}$. One exception to this trend was found for $\Lambda \geq 50 \mathrm{deg}$ at $\alpha=12 \mathrm{deg}$, where values in Figure 4 indicate an overall reduction in drag coefficient by 18 drag counts. At this relatively high angle of attack for $\Lambda=0 \mathrm{deg}$, the winglet would be more susceptible to the onset of flow separation (increased pressure drag) since, for this untwisted wing planform, effective angles of attack would increase toward the winglet tip from downwash from the tip vortex. With winglet rotation out of the wing plane under these conditions, not only does the projected planform span reduce but the angle of attack of the winglet reduces from $\alpha=12 \mathrm{deg}$ (for $\Lambda \leq 0 \mathrm{deg}$ ) to near $\alpha=0 \mathrm{deg}$ (for $\Lambda \approx 75 \mathrm{deg}$ ) as the winglet nears perpendicularity to the oncoming airstream and the wing plane. At this station, therefore, and under these flow conditions, the promotion of flow separation, and therefore increase in pressure drag, would be diminished.

The influence of the reflexed trailing edge of the Zagi 12 airfoil profile used by both the main wing and each winglet on the pitching moment coefficient is also shown in Figure 4. From the plot of $C_{m}$, the pitching moment coefficient is positive at $\alpha=0 \mathrm{deg}$ indicating the effectiveness of the trailing edge at generating a stabilising nose-up pitching moment. $C_{m}$, at this angle of attack, much like the results of $C_{L}$ at the same angle of attack also exhibit a relative insensitivity to change in winglet dihedral angle. This situation does change as aerodynamic loading increases with the reduction in $C_{m}$ with winglet deflection becoming more pronounced for $\alpha \geq 4 \mathrm{deg}$. While clearly showing the characteristics of positive static stability $C_{m_{\alpha}}<0$ 


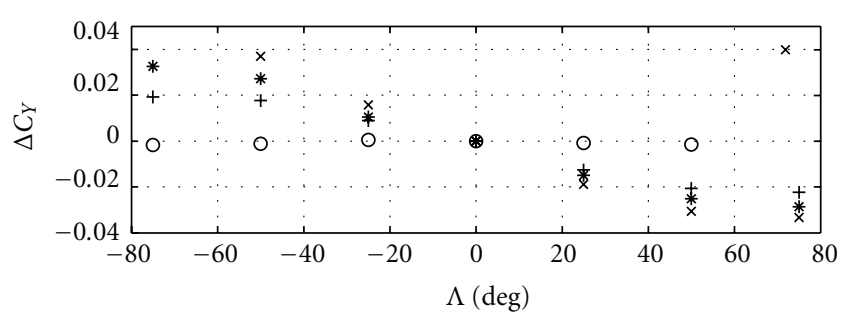

(a)

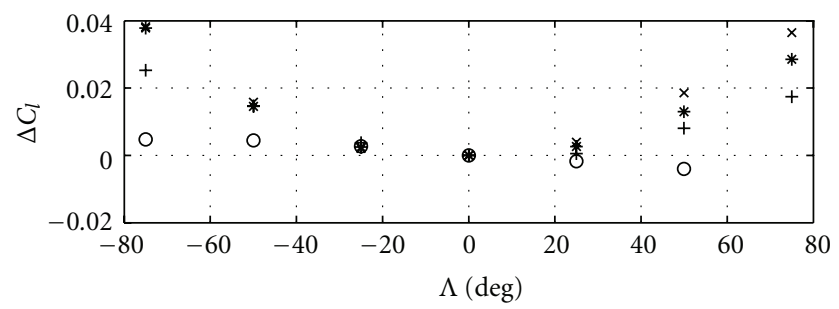

(b)

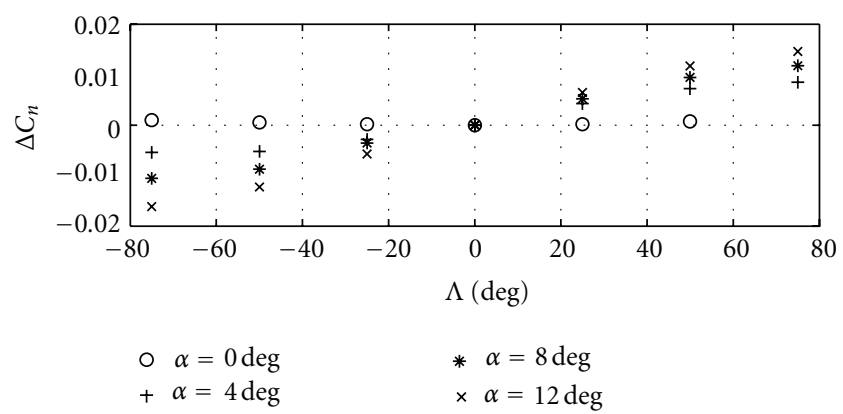

(c)

FIGURE 5: Effect of changing winglet dihedral angle on the lateral static forces and moments, $\operatorname{Re}_{n}=5.53 \times 10^{5}$.

(i.e $C_{m_{\alpha}} \approx-0.49 \mathrm{rad}^{-1}$ for $\Lambda=0 \mathrm{deg}$ ), the deflection of the winglet either below or above the wing plane reduces the level of static stability (i.e., translates the aerodynamic centre $0.28 c$ at $\alpha=0$ deg forward toward the c.g. located at $0.25 c$ ) at all subsequent angles of attack. This reduction reaches a maximum of $\Delta C_{m}=0.03$ (at $\alpha=12 \mathrm{deg}$ and $\Lambda \leq 75 \mathrm{deg}$ ) representing a decrease of $34 \%$ from that found at $\Lambda=0 \mathrm{deg}$.

The level of insensitivity to change in dihedral angle at $\alpha=0$ deg for $\Delta C_{L}, \Delta C_{D}$, and $\Delta C_{m}$ remains unchanged when considering the results obtained for the lateral forces and moments shown in Figure 5. For higher angles of attack, particularly for $\Delta C_{Y}$ and $\Delta C_{n}$, results show an almost linear dependence up to $\Lambda= \pm 50 \mathrm{deg}$ before undergoing, for most results and angles of attack, a small reduction from this linear trend for $\Lambda>50 \mathrm{deg}$. A similar result was found in [16], with this dependency found to result from the reduction in effective angle of attack with winglet rotation (thereby reducing aerodynamic loading) already discussed earlier for the results of $\Delta C_{D}$ and the dependency of these two variables on winglet lift generation with winglet deflection. As expected, the results of $\Delta C_{l}$ show an almost symmetric deviation with variation in winglet dihedral angle due to the inherent connection between $\Delta C_{L}$ and $\Delta C_{l}$ for this configuration. Comparing the maximum roll authority of $\Delta C_{l}=0.0365(\Lambda=75 \mathrm{deg}$ at $\alpha \geq 12 \mathrm{deg}$ giving $\Delta C_{l} / \Delta \Lambda=0.0279 \mathrm{rad}^{-1}$ ) to that of a standard aileron configuration on a typical large transport aircraft of approximately $\Delta C_{l} / \Delta \xi=0.08-0.25 \mathrm{rad}^{-1}$ [17], it appears that the current methodology, per radian deflection, is somewhat inferior with respect to current, traditional roll control systems. However, if control surface angle of deflection is removed from the derivative, and assuming standard aileron deflection magnitudes for a large transport aircraft are upwards of $\xi= \pm 20 \mathrm{deg}$, the ability of the two systems to generate roll moment are found to be more comparable, with results of $\Delta C_{l}=0.027-0.087$ against $\Delta C_{l}=$ 0.0365 for the winglet concept. While the ability of both systems to generate a similar roll moment is evident, ailerons produce this moment more effectively with approximately one-third the deflection magnitude.

A similar condition to that described already for $\Delta C_{l}$ exists for $\Delta C_{n}$. For the swept wing/winglet configuration, the maximum yawing coefficient due to winglet deflection was measured at $\Delta C_{n}=-0.0161$ (or $\Delta C_{n} / \Delta \Lambda=0.0122 \mathrm{rad}^{-1}$ ) for $\Lambda=-75 \mathrm{deg}$ at $\alpha \geq 12 \mathrm{deg}$. This compares with the yaw moment magnitude generated by aileron deflection of the generic transport aircraft already discussed of $\Delta C_{n}=$ 0.005 [18] (calculated with a $C_{L} \approx 1$ ) or $\Delta C_{n} / \Delta \xi=$ 0.0156 . However, it should be noted that typical aileron deflection traditionally generates yaw moment apposing the roll manoeuvre (adverse yaw) but with the winglet deflection above the wing plane (rather than below) similar yaw moment magnitudes are produced $\left(\Delta C_{n}=0.015\right)$ but in this case, assisting the turn manoeuvre.

3.2.1. Influence of $\mathrm{Re}_{n}$ on Static Forces and Moments. With the decision to introduce no artificial boundary layer tripping to the model, a study of the influence of Reynolds number on the static force and moment characteristics was conducted to investigate any changes in the results in this transitional flow regime. Figure 6 shows results at a fixed $\alpha=4 \mathrm{deg}$, and most aerodynamic coefficients show some influence with $\mathrm{Re}_{n}$ with the possible exception of $C_{n}$. $C_{L}$, $C_{D}$, and $C_{m}$ all show only small trends with the results for the lowest and highest Reynolds numbers for $C_{L}$ agreeing to within $2 \%$. For $C_{D}$, there is a reasonably coherent influence of Reynolds number with a general magnitude increase with increasing $\operatorname{Re}_{n}$ of $C_{D}=0.0291,0.0346$, and 0.0379 for $\mathrm{Re}_{n}=$ $5.53 \times 10^{5}, 7.29 \times 10^{5}$, and $8.97 \times 10^{5}$, respectively. Results for $C_{m}$ show some organisation for $\Lambda \leq 0 \mathrm{deg}$, with the higher $\mathrm{Re}_{n}$ producing lower magnitudes of pitching moment coefficient; however, this was not evident for $\Lambda>0$ deg with the more disordered trend being reestablished. For $\Delta C_{Y}$, the influence of the change in $\mathrm{Re}_{n}$ is to increase the effectiveness of the winglet to produce side force for $\Lambda \leq 0$ deg with the reverse true for $\Lambda>0 \mathrm{deg}$. A clear deviation in the general trend is also shown for $\Lambda>0$ deg in $\Delta C_{l}$ with results for the lowest $\mathrm{Re}_{n}$ showing approximate symmetry before becoming more asymmetric and biased towards winglet up conditions for $\Lambda \geq 25$ deg. 


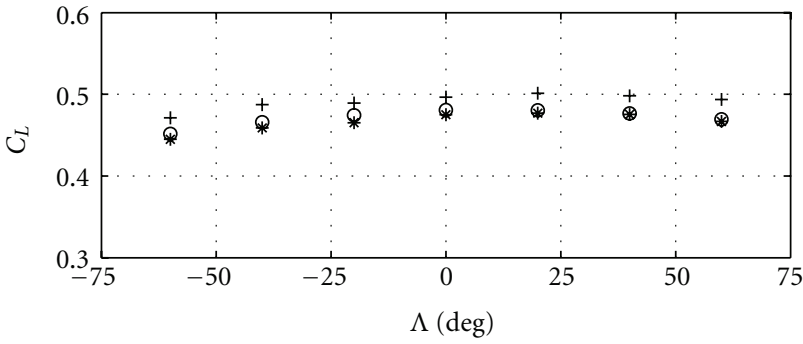

(a)

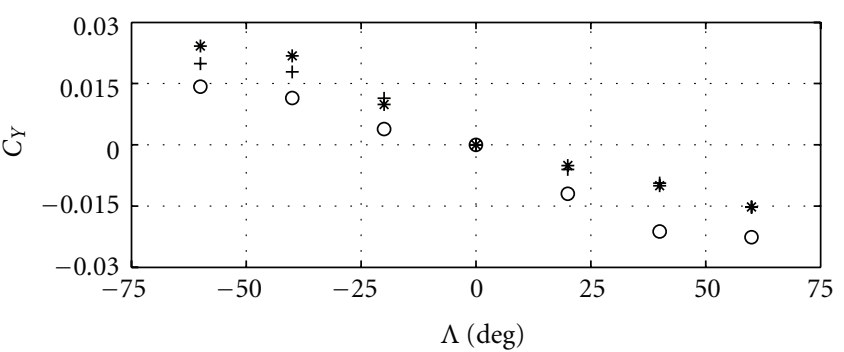

(c)

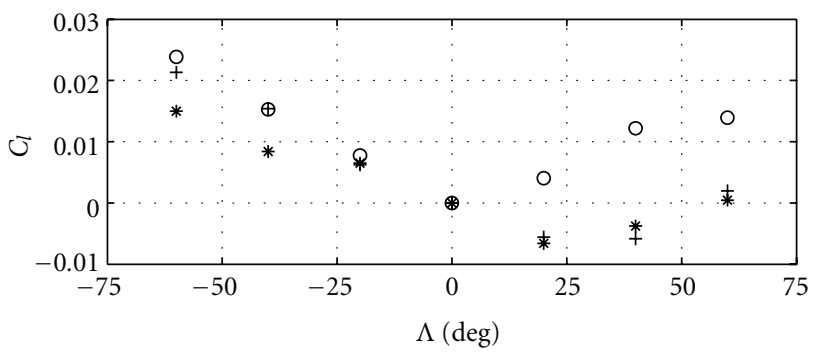

$-\mathrm{Re}_{n}=5.53 \times 10^{5}$
$+\mathrm{Re}_{n}=7.29 \times 10^{5}$
* $\mathrm{Re}_{n}=8.97 \times 10^{5}$

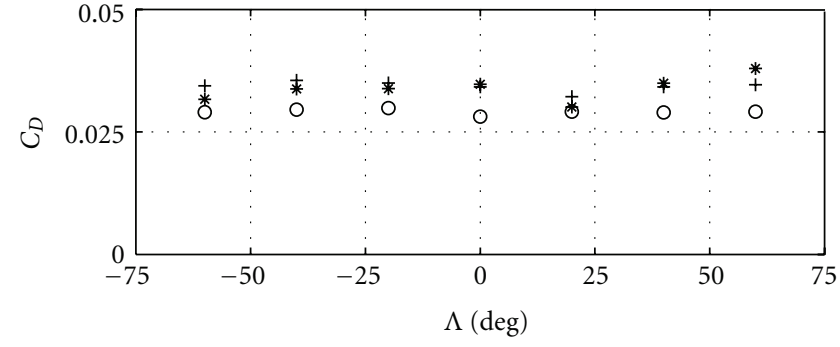

(b)

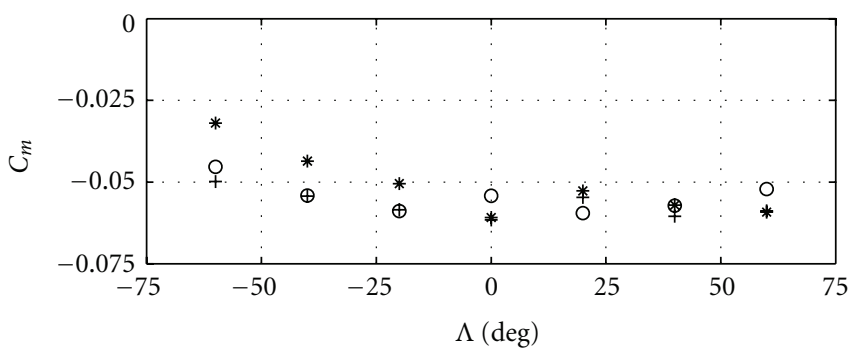

(d)

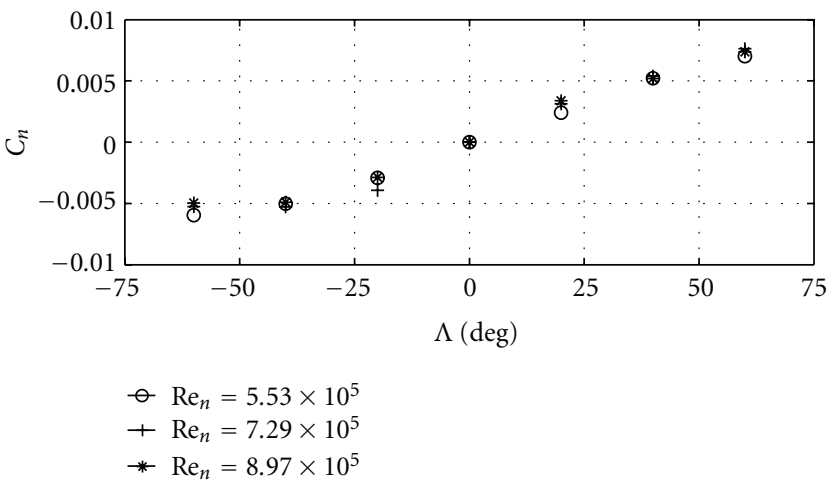

(f)

FIGURE 6: Influence of Reynolds number on the static forces and moments $\alpha=4 \mathrm{deg}$.

3.3. Wing/Winglet Surface Pressures. To explore further the capabilities of the wing/winglet combination at generating control forces and moments described in the previous section, both the surface pressure measured and the change in surface pressure with winglet deflection on the upper surface of the starboard wing/winglet combination are presented in Figures 7-9. On first inspection, the baseline $C_{p}$ results at both angles of attack (Figure 7) show successive minimum peaks toward the leading edge of the model reducing to near $C_{p}=0$ towards the trailing edge of the wing. At stations $20\left(C_{p}=0.0747\right), 25\left(C_{p}=0.0928\right)$ and 37 $\left(C_{p}=0.066\right)$, which were located in close proximity to the trailing edge, surface pressures indicated small positive values indicating the influence of the reflex trailing edge profile used on the surface pressures creating the noseup pitching moment shown in Figure 4 and discussed in Section 3.2. At the spanwise station most inboard for $\alpha=$
$8 \mathrm{deg}$, the peak in the minimum pressure was found to occur at station 2 with $C_{p}=-0.998$ moving to $C_{p}=-1.313$ at station 14 to the maximum negative pressure measured (station 32) of $C_{p}=-1.519$. This level of negative pressure coefficient was generally maintained on the winglet itself as well $\left(C_{p}=-1.362\right.$-station $38, C_{p}=-1.374$-station 50$)$, which would be expected as the chosen wing configuration was untwisted (wingtip, more heavily loaded). At station 32 , located just prior to the wing/winglet interface juncture toward the leading edge, the magnitude of the peak was found to be more than 11\% higher than that found from the nearest neighbour (station 26 with $C_{p}=-1.311$ ) suggesting the existence of a local area of flow acceleration resulting (most probably) from interaction between the oncoming flow and the inboard, leading edge face of the interface support at $y=600 \mathrm{~mm}$. This area of increased suction at this spanwise and chordwise location was also found for the case 


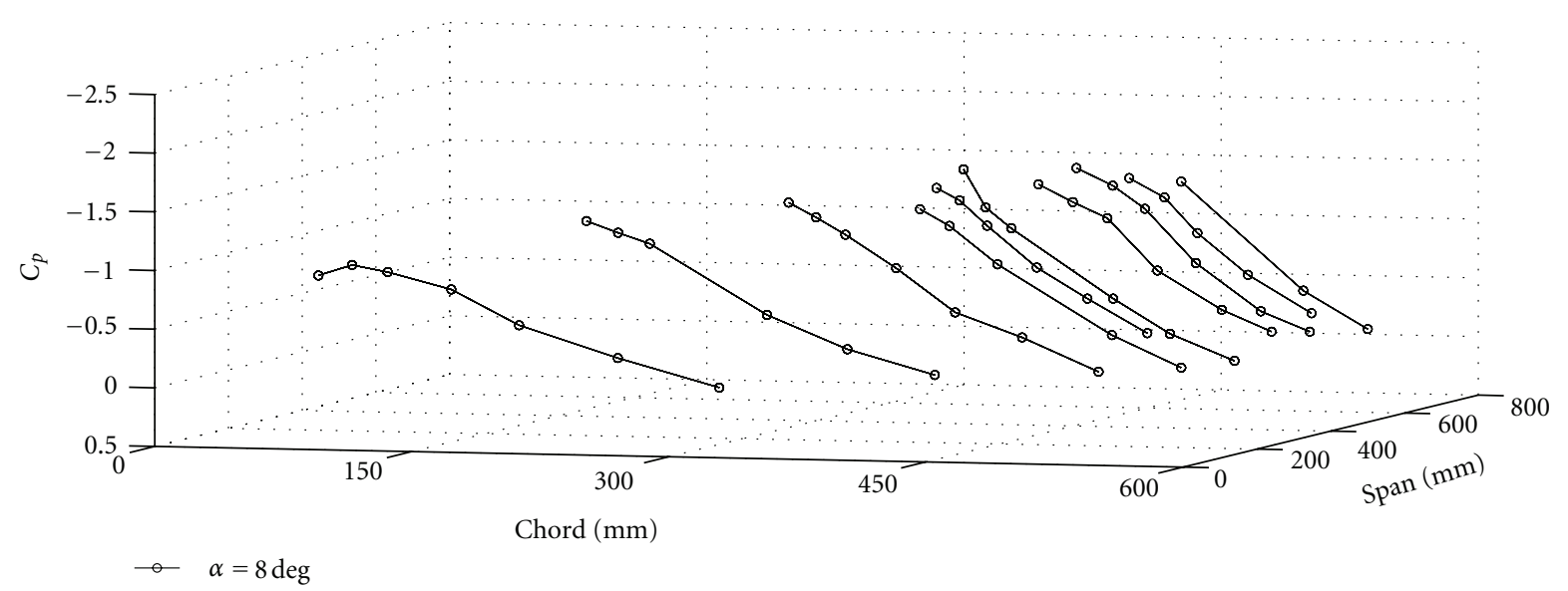

(a)

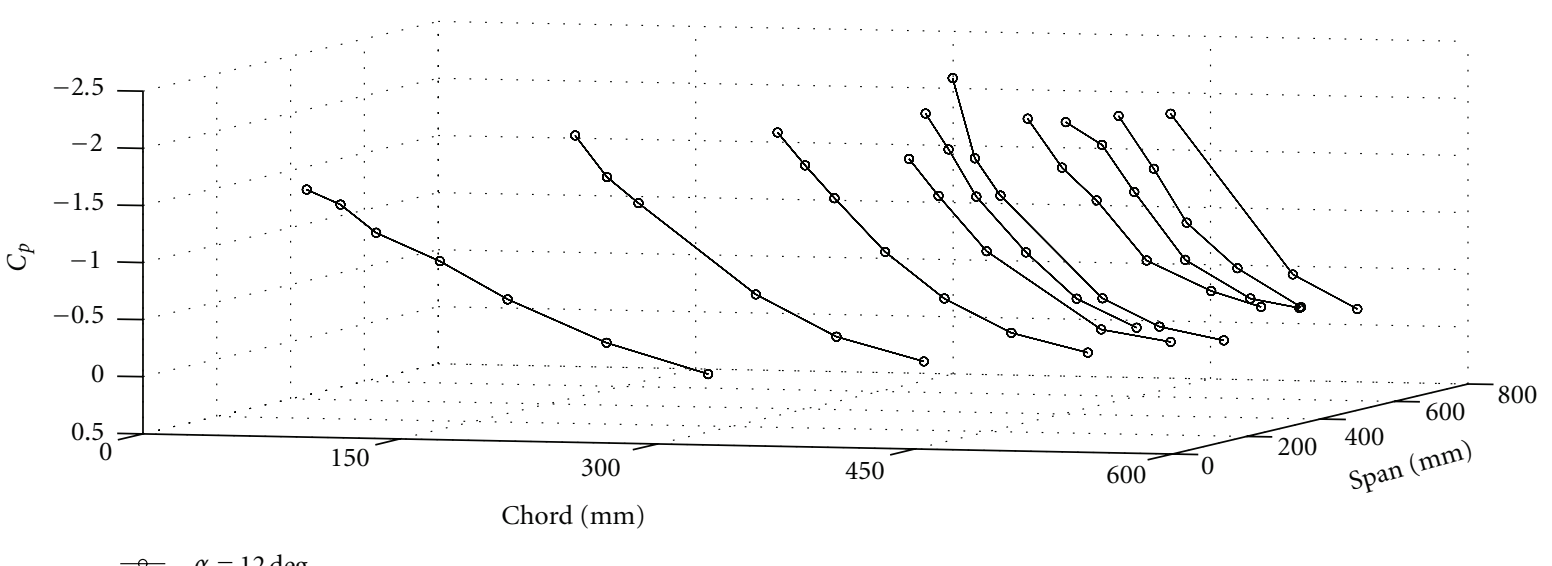

(b)

FIGURE 7: Wing/winglet surface pressures with $\Lambda=0 \mathrm{deg}, \mathrm{Re}_{n}=5.53 \times 10^{5}$.

of $\alpha=12 \mathrm{deg}$; however, at this angle of attack, the minimum pressure magnitude was found to be significantly enhanced with a $C_{p}=-2.273$.

Comparing further the results from both angles of attack, the surface pressure distribution for $\alpha=12$ deg shows markedly more severe minimum suction pressures across the entire span of the wing/winglet combination over that observed for the $\alpha=8 \mathrm{deg}$ case. From a qualitative perspective, the pressure distributions (as well as the minimum pressure position) shown at $\alpha=12 \mathrm{deg}$ also indicate a marked shift in bias toward the leading edge, which would be expected as the leading edge portion of the wing/winglet becomes more loaded with angle of attack increase. It is also evident from both subfigures in Figure 7, that the effect of increased spanwise distance from the wing root on the pressure distribution seems also to be moderate with the change in minimum pressure magnitude found to increase by a relatively small amount from the second outboard chordwise station from the wing root $\left(C_{p}=-1.939-\right.$ station 8) to station $21\left(C_{p}=-1.973\right.$ - station 21) thereafter reducing slightly at stations $44\left(C_{p}=-1.889\right)$ and $50\left(C_{p}=\right.$ $-1.871)$.

Having set out the baseline conditions for $\Lambda=0 \mathrm{deg}$ at these angles of attack, the influence of actively rotating the winglet both above and below the wing plane though various levels of dihedral are presented in Figures 8 and 9. For clarity of presentation, the results measured on the winglet are presented without the relevant position change out of the wing plane, which occurred in reality due to the winglet rotation. Depending on the level of rotation of the winglet, and whether the winglet is rotated below or above the winglet, several different and unique effects on both the wing and winglet surface pressure distributions are evident. Firstly, for small deflections in dihedral, the influence on both the wing and winglet surface pressure distributions were only moderate. Under these conditions, the variation 


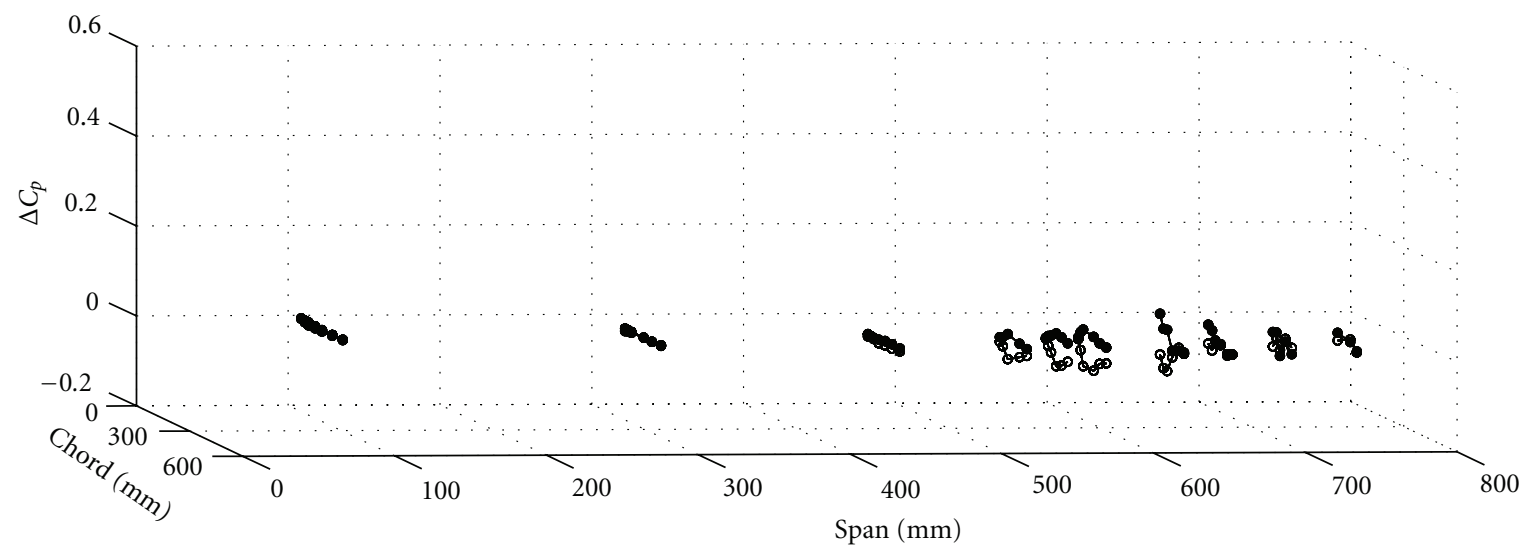

$$
\longrightarrow \Lambda=0 \text { to }-25 \mathrm{deg}
$$

(a)

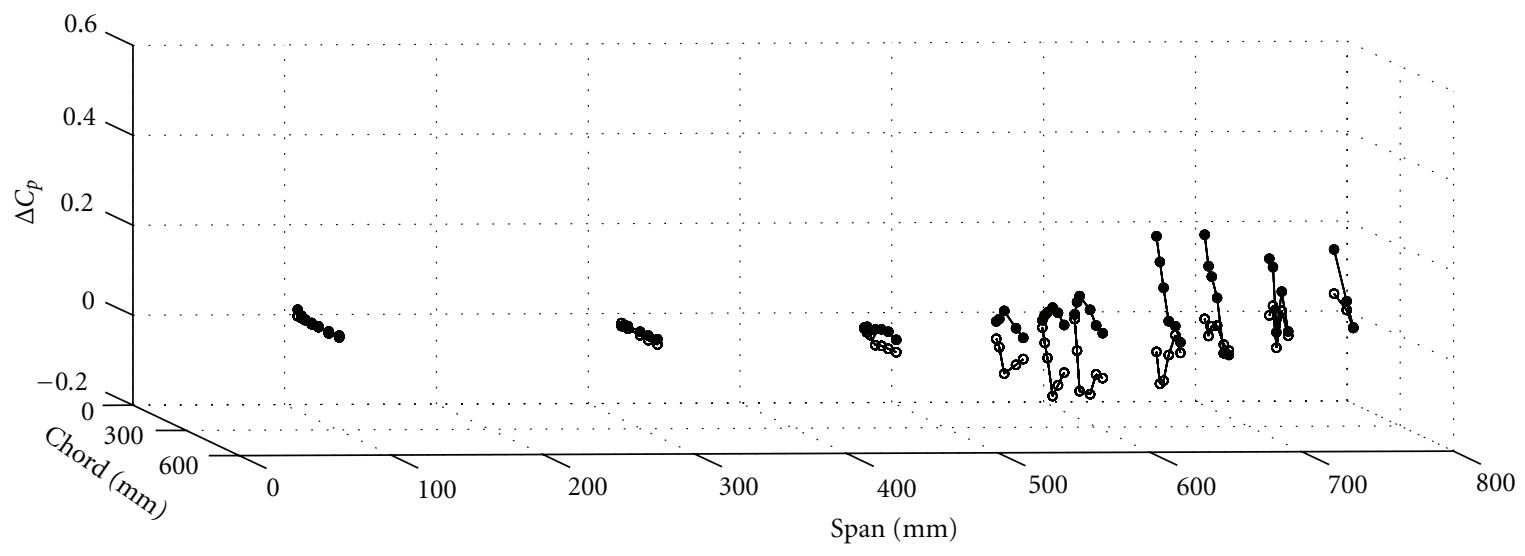

$-\Lambda=0$ to $-50 \mathrm{deg}$
$-\Lambda=0$ to $50 \mathrm{deg}$

(b)

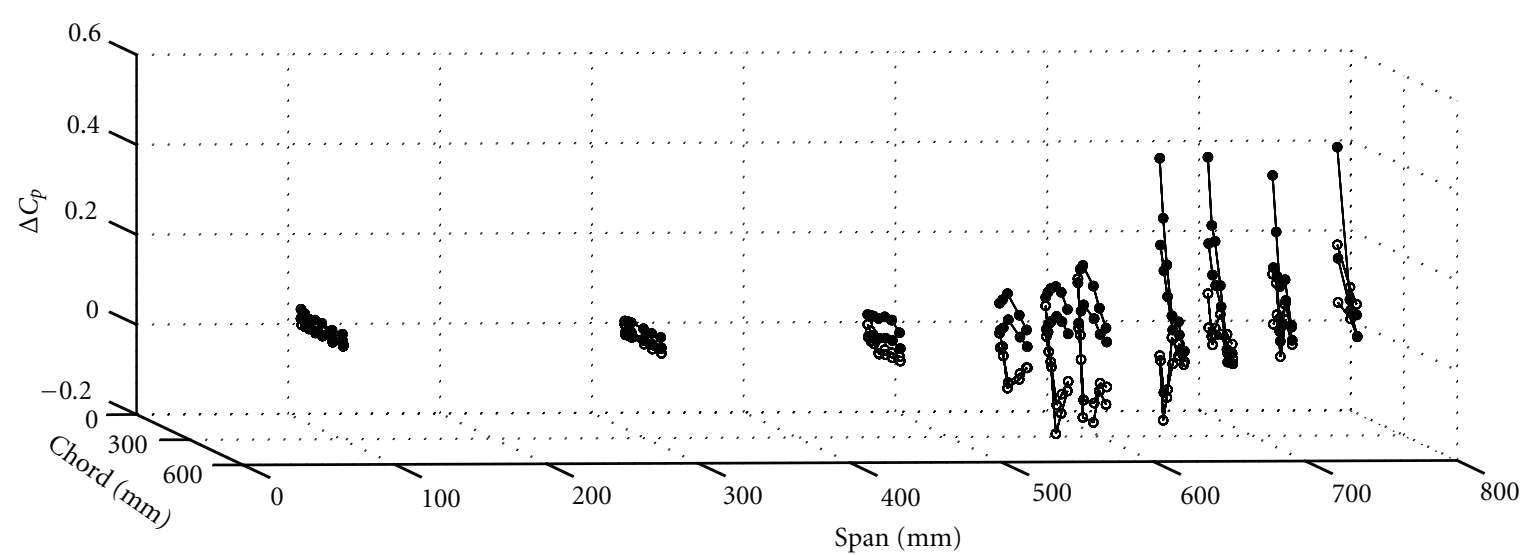

$\longrightarrow \Lambda=0$ to $-75 \mathrm{deg}$

- $\Lambda=0$ to $75 \mathrm{deg}$

(c)

FIGURE 8: Change in Wing/winglet surface pressures for $\alpha=8 \mathrm{deg}, \operatorname{Re}_{n}=5.53 \times 10^{5}$. 


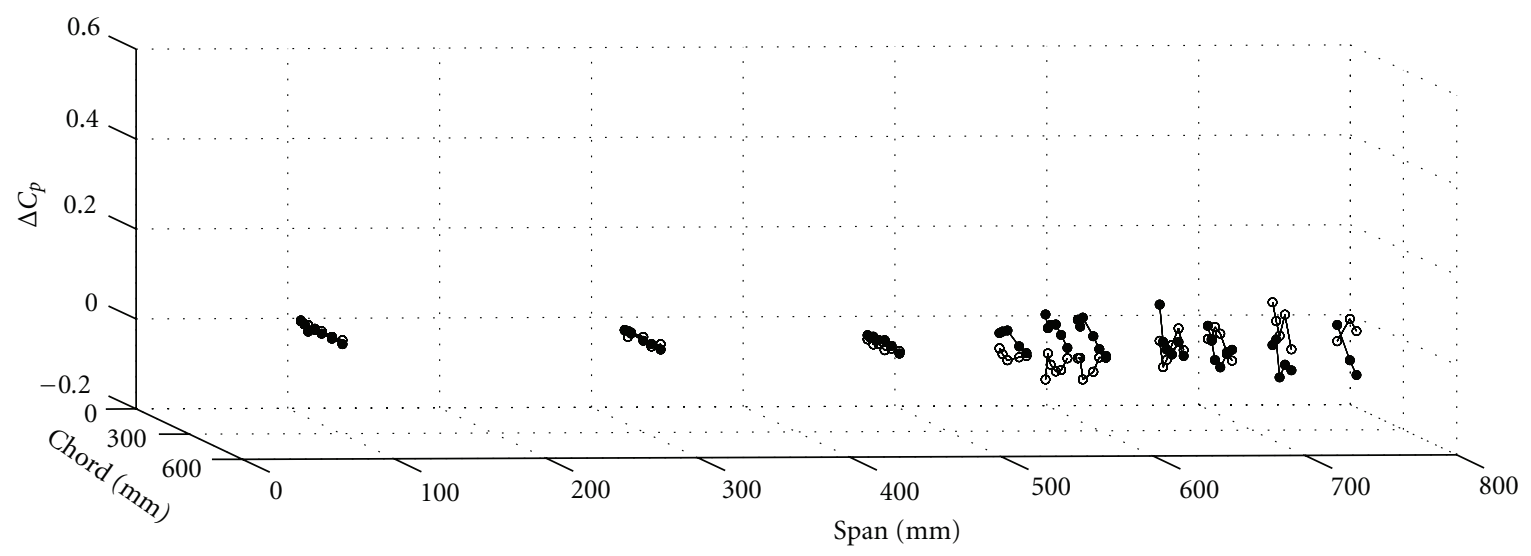

$\rightarrow \Lambda=0$ to $-25 \mathrm{deg}$

- $\Lambda=0$ to $25 \mathrm{deg}$

(a)

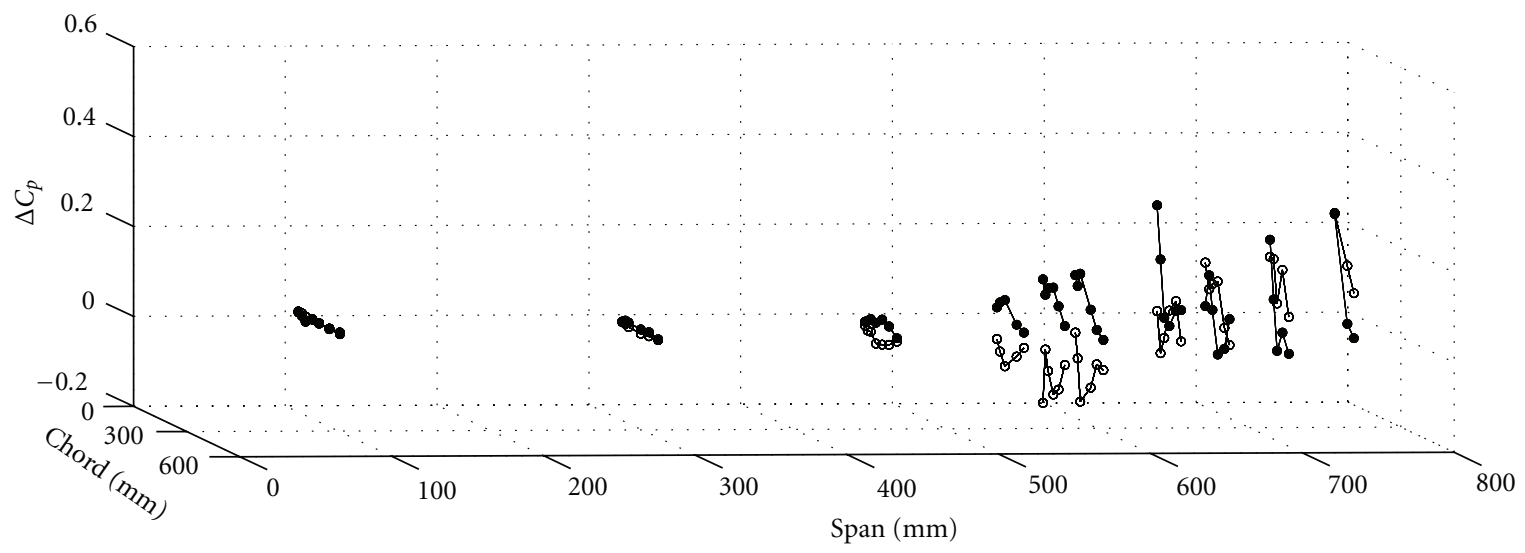

$\rightarrow \Lambda=0$ to $-50 \mathrm{deg}$

○- $\Lambda=0$ to $50 \mathrm{deg}$

(b)

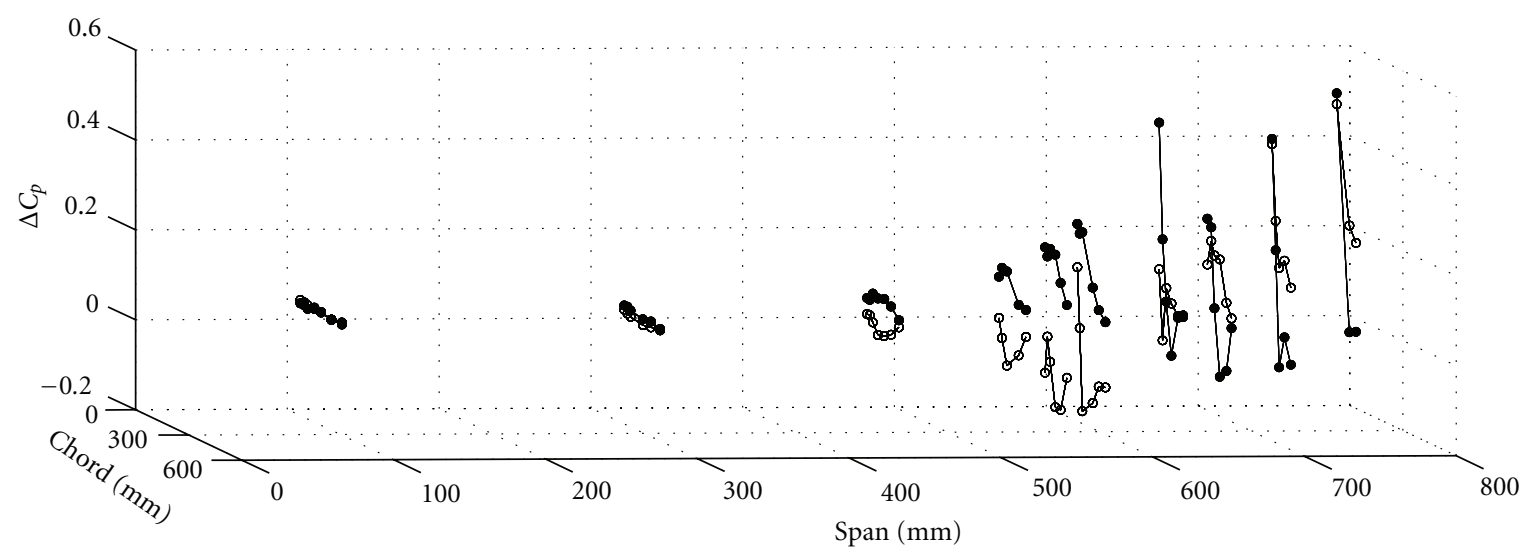

$\bullet \Lambda=0$ to $-75 \mathrm{deg}$

$-\Lambda=0$ to $75 \mathrm{deg}$

(c)

FIGURE 9: Change in Wing/winglet surface pressures for $\alpha=12 \mathrm{deg}, \operatorname{Re}_{n}=5.53 \times 10^{5}$. 
in the three most inboard spanwise stations (closest to the wing root) is almost negligible with a maximum change to the $C_{p}$ distribution being less than $\pm 4 \%$ (located at station 19). However, the influence of winglet deflection, even at these very small levels of winglet deflection of $\Lambda \pm 25 \mathrm{deg}$, begins to show a significant level of influence on the surface pressure distribution at the three spanwise measurement planes just inboard of the wing/winglet interface support. Within this localised wing area, both deflections above and below the wing plane have a measurable influence on the pressure distribution, the maximum deviations from the mean $C_{p}$ values being larger for winglet deflection above the wing plane $\left(\Delta C_{p}=-0.0487\right.$ or $-4.9 \%$ at station 34 for $0 \leq \Lambda \leq 25 \mathrm{deg}$ ) than that measured below the wing plane ( $\Delta C_{p}=0.0325$ or $3.2 \%$ at station 34 for $0 \leq \Lambda \leq-25 \mathrm{deg}$ ) as the winglet confines and helps to maintain negative upper surface pressure magnitudes. On the winglet itself, under these conditions, winglet deflection at these levels appears only to have a measurable effect on areas of winglet wetted area localised in close proximity to the interface support (stations 38-41) with a maximum deviation of $\Delta C_{p}=$ 0.0683 or $5 \%$ at station 38 .

Considering more extreme winglet dihedral deflections for the $0 \leq \Lambda \leq \pm 50 \mathrm{deg}$ and $0 \leq \Lambda \leq \pm 75 \mathrm{deg}$ cases also shown in Figure 8, larger winglet deflections have both a more significant and more disruptive effect, not only for spanwise stations close to the interface support juncture but an increasing influence on further inboard stations. This influence, for winglet deflections of $\Lambda= \pm 75 \mathrm{deg}$, is shown to extend, with significant effects, out to now four spanwise locations inboard of the wing/winglet interface support (450 $\leq y \leq 600 \mathrm{~mm}$ ), with minor, but detectable, changes evident for the remaining spanwise measurement locations on the main wing $(y=100 \mathrm{~mm}$ and $y=300 \mathrm{~mm})$. The impact of winglet rotation on the upper surface distribution also appears to have the most dominant influence at more mid-chord measurement stations rather than at either the leading or trailing edge of the main wing with all mid-chord stations for most test conditions being substantially greater in magnitude that those close to the leading or trailing edges. The ability of this active winglet setup to influence the main wing pressure distribution suggests that, with more detailed design, this particular control methodology could serve as an effective and efficient means of aerodynamic load alleviation and induced drag minimisation during the cruise phase of flight where fuel burn and aircraft weight reduction is known with reasonable accuracy.

The influence of winglet deflections from planar to above the wing plane at $\alpha=8 \mathrm{deg}$ have approximately the same effect on the upper surface pressure distribution on the baseline wing than deflections below the wing plane. For both $\Lambda=50 \mathrm{deg}$ and $75 \mathrm{deg}$, maximum changes in surface pressure were found to both occur at station 29 at $\Delta C_{p}=-0.11$ and -0.175 , respectively. This corresponds to a maximum change for $\Lambda=0 \mathrm{deg}$ to $\Lambda=-50 \mathrm{deg}$ and -75 deg of $\Delta C_{p}=0.105$ and 0.195 , respectively (station 34 ), and shows an almost linear dependency of winglet deflection on the maximum change in upper wing surface pressure. However, the results shown in Figure 9 deviate somewhat from this trend with the influence of maximum winglet deflection below the wing plane found to have almost double the maximum surface pressure magnitude change $\left(\Delta C_{p}=\right.$ 0.27 at station 32) than the corresponding result for $\Lambda=$ $75 \mathrm{deg}\left(\Delta C_{p}=-0.14\right.$ at station 34$)$.

Comparing the winglet upper surface distributions from both Figures 8 and 9, the somewhat ordered and uniform changes $\left(\Delta C_{p} \geq 0\right.$ for $\Lambda \leq-75 \mathrm{deg}$ and $\Delta C_{p} \leq 0$ for $\Lambda \leq 75 \mathrm{deg}$ ) evident for all winglet deflection angles at $\alpha=8 \mathrm{deg}$ all but disappears for $\alpha=12 \mathrm{deg}$. For $\alpha=8 \mathrm{deg}$, the maximum change in $\Delta C_{p}$ for $\Lambda=0 \mathrm{deg}$ to $\Lambda=-75 \mathrm{deg}$ $\left(\Delta C_{p}=0.434\right.$ at station 38$)$ was found to be approximately three times that of $\Delta C_{p}$ for $\Lambda=0 \mathrm{deg}$ to $\Lambda=75 \mathrm{deg}$ $\left(\Delta C_{p}=-0.143\right.$ at station 32$)$ representing a substantial shift from the almost equal and opposite effect found for results on the baseline wing with winglet deflection either above and below the wing plane. Additionally, in a situation quite distinct from the influence of winglet rotation on the baseline wing element, the impact of winglet rotation on the winglet itself seems to bias toward the leading edge, particularly for $\Lambda<0$ deg, which seems reasonable given the differences expected in aerodynamic loading as the effective angle of attack of the winglet is changed from the baseline wing angle of attack initially ( $\Lambda=0 \mathrm{deg}$ ) to $\alpha \approx 0 \mathrm{deg}$ at maximum winglet deflection magnitudes. For $\alpha=12 \mathrm{deg}$, a further increase of $\Delta \alpha=4 \mathrm{deg}$ in angle of attack from $\alpha=8 \mathrm{deg}$ leads to a marked increase in disorder in winglet upper surface pressure providing further evidence to the possibility that aerodynamic conditions are being encountered that are reducing winglet effectiveness at producing ultimate roll moment and/or promoting regions of flow separation.

\subsubsection{Wing/Winglet Surface Pressure Dynamics. To aid in} the interpretation of the results presented in Section 3.3, examples of the real-time surface pressures during a fast winglet actuation case from an initial condition of $\Lambda=0 \mathrm{deg}$ to $\Lambda=60 \mathrm{deg}$ are included in Figure $10(\alpha=12 \mathrm{deg})$ for this case shown, the input signal into the actuation servos to rotate the winglet was initiated at approximately $t=8.7 \mathrm{sec}$ with the effects of the winglet movement found, from close inspection of the results, to last for approximately $0.3 \mathrm{sec}$ before steady-state conditions were reestablished. In the example result presented, and in general agreement with the discussion in Section 3.3, stations on the winglet itself (stations 38-49) show an overall decrease in magnitude with the majority of stations on the main wing registering a net increase (particularly stations 34 and 35) with winglet rotation above the wing plane. It is interesting to note that at all stations prior to actuation, results from the pressure signals do indicate a general unsteadiness (most notable at stations 38 and 44, which are located closest to the leading edge) in the flowfield at this relatively high angle of attack giving further evidence to the inferred conclusions made in the previous section for Figure 9 and discussed in Section 3.3 that there may exist regions of flow separation on the wing/winglet combination for $\Lambda=0 \mathrm{deg}$. This result can also be supported when considering the influence of winglet effective angle of attack change with winglet rotation on the degree of signal unsteadiness change on both the wing and 


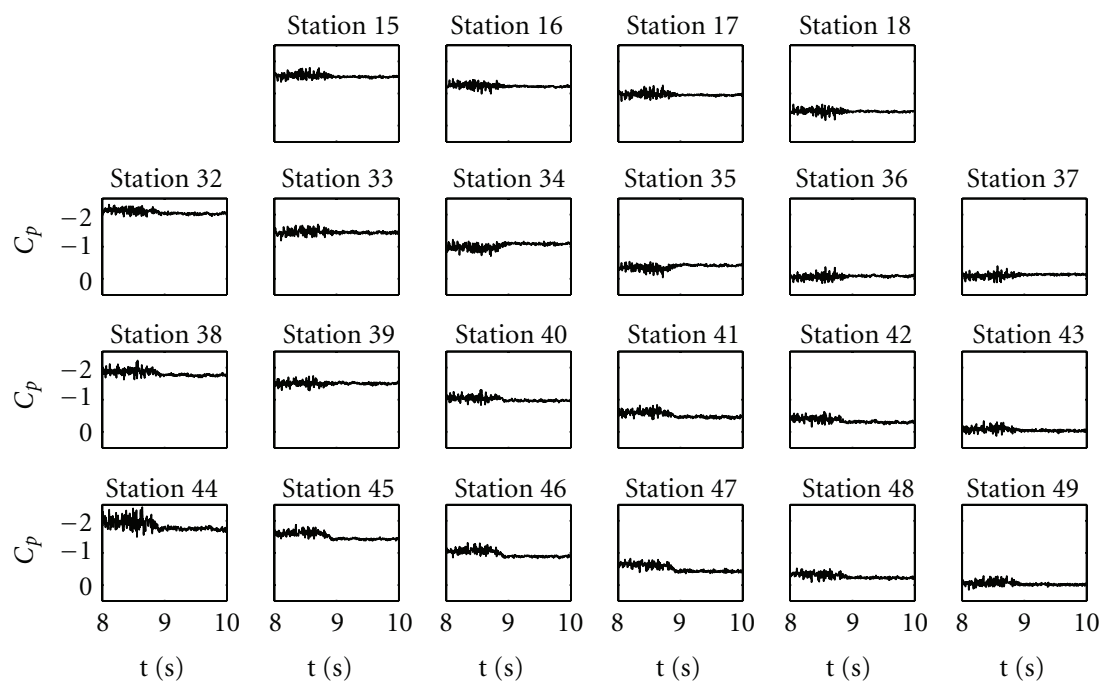

FIGURE 10: Real-time surface pressures near to the wing/winglet interface, $\alpha=12 \mathrm{deg}, \operatorname{Re}_{n}=5.53 \times 10^{5}$.

winglet before and after winglet rotation. Analysis of the root mean square fluctuations made prior to winglet rotation $(t<8.7 \mathrm{sec})$ to those measured after $(t>9 \mathrm{sec})$ indicated that unsteadiness magnitudes decreased by more than $200 \%$ under conditions of $\Lambda=0$ deg to $60 \mathrm{deg}$.

3.4. Load Alleviation and Other Capabilities. From the results and discussion presented in Section 3.3, together with the ability of the active wing/winglet to provide first-order control forces and moments about the aircraft axes, it seems reasonable to the authors that the placement and use of these unconventional control surfaces at the wing-tips for control could also be exploited at secondary, more microscopic levels to improve aircraft performance and efficiency over a range of typical aircraft mission segments. Firstly, as suggested by the results presented in Figures 8 and 9, the winglet dihedral angle changes the upper surface wing loading distribution, and with careful initial design, could be used as a tool for manoeuvre load alleviation [19]. Within this regime of high$\mathrm{g}$ manoeuvring, the adjustment of the winglet either above or below the wing plane, while reducing the net lift created marginally $\left(\Delta C_{L}=0.03\right.$ or $\Delta C_{L} \approx 0.06$ if both winglets are deflected in unison) which is not ideal for this manoeuvre, does produce a substantial reduction of the root bending moment (RBM) when compared to the planar configuration. From analysis and integration of the upper surface pressure distributions only, results presented in Figure 11 show that for relatively high angles of attack, where typically such manoeuvres can be performed, that substantial reductions of more than $25 \%$ were achievable for the largest winglet deflections below the wing plane. Considering this level of reduction for a large aircraft, and noting that generally the wing structure for this type of aircraft is sized by this manoeuvring requirement [19], the use of this technology in this alleviation capacity could lead to structural weight savings of up to $2 \%[15,19]$. This reduction in structural weight would also conceivably offset the inevitable structural wing weight increase expected from the integration of the active winglet rotation actuation mechanism and support structure. It should also be noted that even if this technique is utilised for manoeuvre load alleviation at more moderate winglet deflection magnitudes of $\Lambda=-25 \mathrm{deg}$, results still indicate reasonable levels of maximum RBM reduction of up to $4 \%$.

Secondly, with winglet dihedral angle adjustable, winglets can be configured within the plane of the wing to both improve and augment lift for take-off and initial climb while minimising induced drag, as well as maintaining full extension during cruise to also provide minimum-induced drag conditions. At take-off and climb-out, induced drag can account for up to $80 \%$ of the overall aircraft drag for large transport operations [20]. The ability to extend the winglets to the planar configuration at this condition may provide useful benefits to both reduce take-off distances (extra lift and lower drag to achieve take-off conditions earlier while generating lower noise [20]) and/or allow extra payload capacity for the same take-off distance. As typically root bending moment is not near maximum at take-off and climb-out as the flight speed is still low, the weight saving gained in the manoeuvre load analysis discussed earlier may be preserved. Additionally, upon landing, both winglets could be stowable at maximum deflection magnitudes either above or below the wing plane to preserve the stringent maximum aircraft spatial requirements at airports.

Lastly, the ability of finer winglet rotation adjustment either above and below the wing plane to directly affect the spanwise loading on the main wing seems ideally suited toward the less macroscopic and more microscopic load adjustments required as aircraft fly long cruise mission segments. During these segments, where fuel weight and overall aircraft lift requirements diminish, a means for fine adjustment of aircraft lift requirements, while maintaining optimum drag, would provide significant operational benefits. For the active winglet concept, as already mentioned 


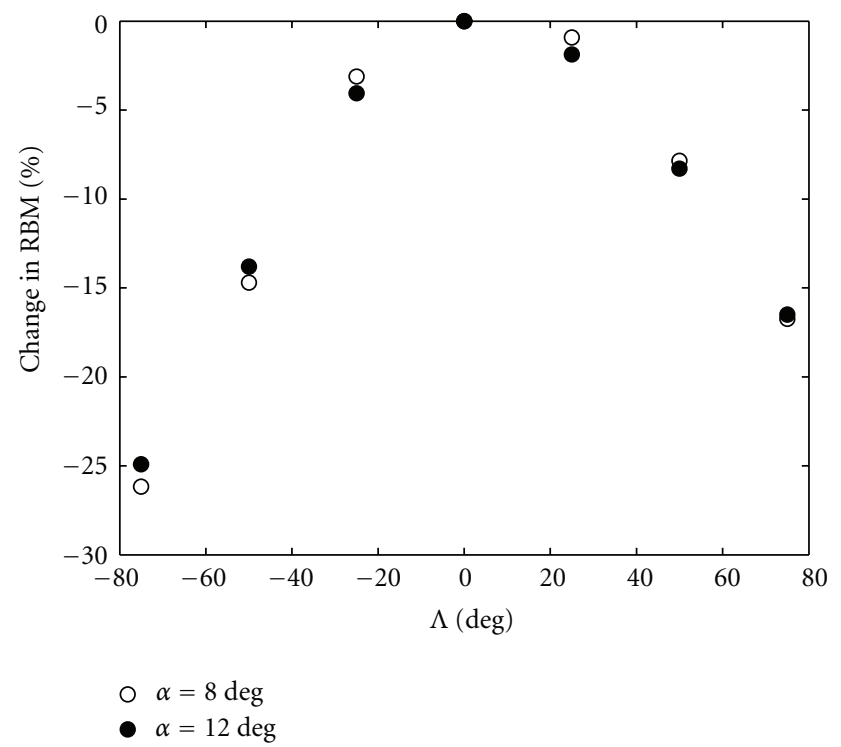

FIGURE 11: Percentage change in RBM from winglet rotation, $\operatorname{Re}_{n}=5.53 \times 10^{5}$.

in previous sections, maximum levels of winglet dihedral angle deflection considered in this work do have a reasonable influence on overall lift coefficient with $\Lambda \pm 75 \mathrm{deg}$ producing $\Delta C_{L} \approx 0.06$ (if both winglets are deflected in unison) or more than $12 \%$ at $\alpha=4 \mathrm{deg}$. While being significantly lower than typical long haul flight weight reductions of $30 \%$ corresponding to $\Delta C_{L}=0.3-0.4$ [21], from Figure 4 which indicates a null or small net drag benefit for $\alpha=4 \mathrm{deg}$, the facility may exist for some level of optimisation of loading requirements for improved efficiency during this type of mission segment.

As is well known through classical linearised theory, the requirements for minimum-induced drag (for the same lift, weight, wing span) requires an elliptical spanwise lift distribution [20]. To further investigate the possibilities of achieving and maintaining this type of distribution, the variation in sectional lift coefficient distribution (obtained again from only upper surface pressure distributions) with change in winglet dihedral angle was calculated and is presented in Figure 12. As already mentioned in Section 3, and shown in these sectional lift distribution results, the use of a moderately tapered wing/winglet combination with no wash-out and constant airfoil section results in an aerodynamic loading bias toward the tip region of the combination. While strictly not elliptical in nature, useful information can still be gained from the degree of adjustment capable of using the active winglet concept.

From first inspection for all results, the influence of winglet deflection on $c_{l}$ below $y / b<0.8$ is moderate and subtle. This trend, however, changes considerably further outboard of this spanwise limit, with positive winglet deflections resulting in more intense sectional lift magnitudes (particularly for $\Lambda \geq 50 \mathrm{deg}$ ) above conditions experienced for $\Lambda=0$ deg as the flow is confined by winglet rotation into the upper surface plane preserving the low pressure regions on the upper surface of the baseline wing near the wing/winglet interface support $(0.9<y / b<1)$. An approximate equal and corresponding decrease in $c_{l}$ magnitude within this spanwise region also occurs for $\Lambda \leq$ $-50 \mathrm{deg}$. With these results and their location within this sensitive region with respect to drag reduction [20], it seems reasonable to the authors that there could exist some facility to adjust these sectional lift coefficient magnitudes (more elliptical or otherwise and assuming sufficient initial wing design effort) and to adjust and/or optimise the induced drag component of the overall aircraft drag during some mission segments. For $\alpha=8 \mathrm{deg}$, this level of achievable variation in $c_{l}$ magnitude was calculated at more than $\pm 15 \%(y / b=0.96)$ for $\Lambda= \pm 75 \mathrm{deg}$ from the planar configuration with this metric decreasing marginally for $\alpha=12$ deg to over $\pm 12 \%$. Within the winglet spanwise region $(y / b>1$ and $y / b<1.3)$, the differences in $c_{l}$ are also significant, but for this case, unlike the results within the $0.9<y / b<1$ region on the wing, excursions from both $\Lambda>0$ deg and $\Lambda<0$ both show both show varying levels of reduction of $c_{l}$ magnitude (up to $-20 \%$ at $\alpha=8 \mathrm{deg}, \Lambda=-75 \mathrm{deg}$ ) from the $\Lambda=0 \mathrm{deg}$ baseline.

\section{Conclusion}

The use of articulated winglets on a baseline swept wing configuration to both produce first-order control forces and moments as well as provide load alleviation capabilities to the combination has been experimentally investigated in this paper. From force and moment results taken from the model together with dynamic surface pressure data taken from the upper wing and winglet surfaces, the concept gives good evidence that the methodology can provide adequate roll control authority as well as a significant ability to adjust and 

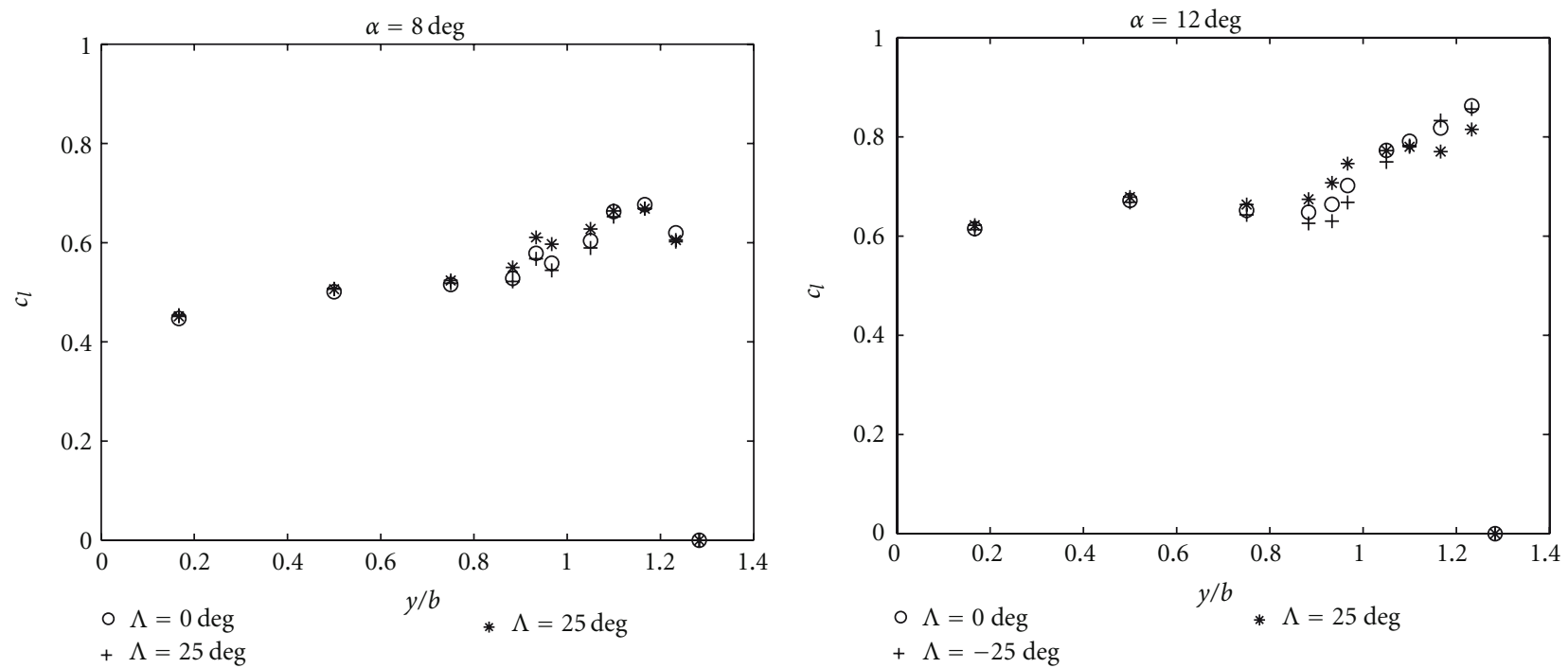

(a)

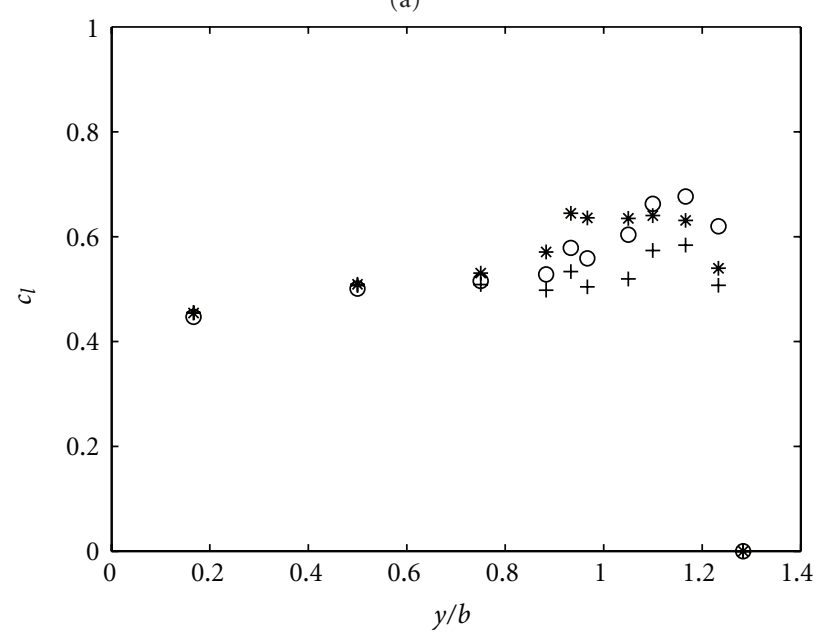

(b)

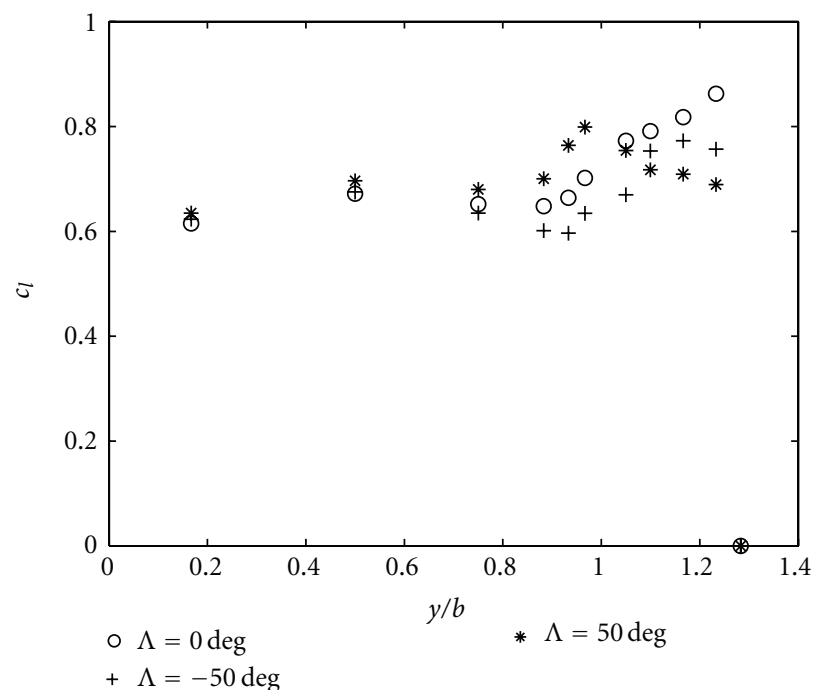

(c)

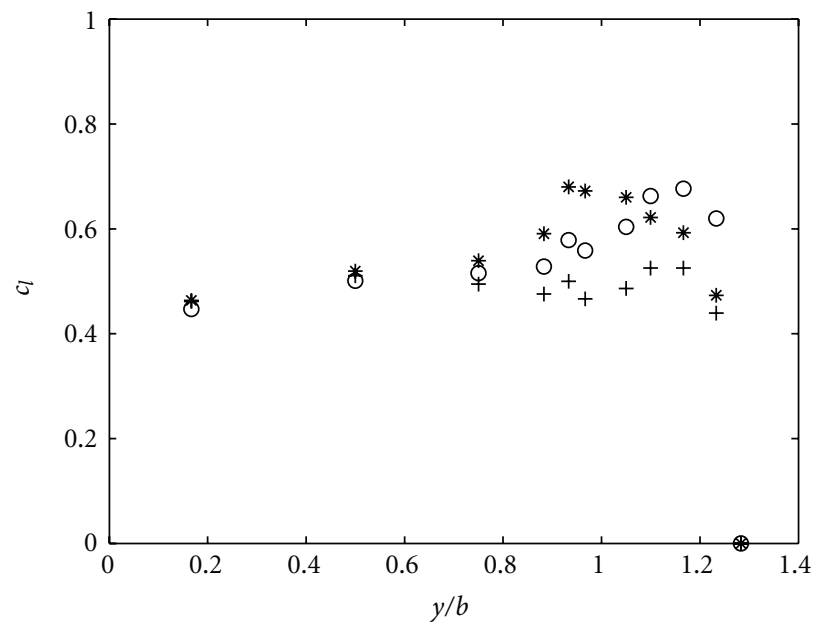
$\circ \Lambda=0 \mathrm{deg}$
* $\Lambda=75 \mathrm{deg}$
$+\Lambda=-75 \mathrm{deg}$

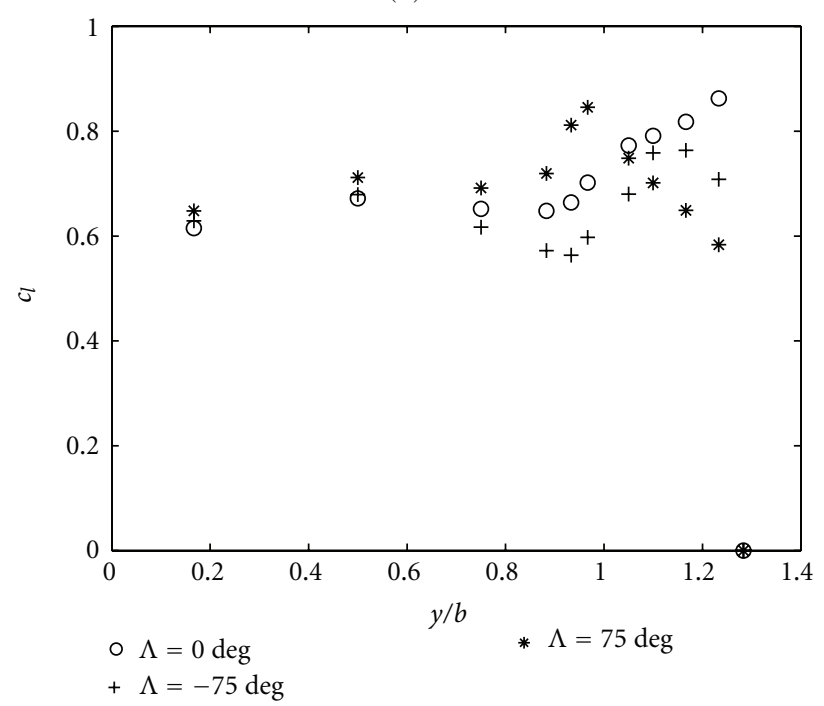

(e)

(f)

FIGURE 12: Sectional lift coefficient distributions for $\alpha=8 \mathrm{deg}$ and $\alpha=12 \mathrm{deg}, \operatorname{Re}_{n}=5.53 \times 10^{5}$. 
tailor the lift distribution for application to second-order performance and efficiency enhancements.

\section{Nomenclature}

$b$ : Structural semispan of swept wing/winglet $\mathrm{mm}$

$C_{D}$ : Drag coefficient

$C_{L}$ : Lift coefficient

$c l$ : Sectional lift coefficient

$C_{l}$ : Rolling moment coefficient

$C_{m}$ : Pitching moment coefficient

$C_{n}$ : Yawing moment coefficient

$C_{p}$ : Pressure coefficient

$C_{Y}$ : Side force coefficient

$t$ : time, sec

$\alpha$ : angle of attack, deg

$\Lambda$ : Dihedral angle of the winglet measured relative to wing plane, deg

$\xi$ : Aileron deflection, positive starboard down, deg

$y$ : Spanwise station from wing root, $\mathrm{mm}$

$\Delta$ : Change or difference.

\section{Acknowledgment}

This work has been supported by a Marie-Curie excellence research Grant MEXT-CT-2003-002690 funded by the European Commission.

\section{References}

[1] D. McRuer and D. Graham, "Flight control century: triumphs of the systems approach," Journal of Guidance, Control, and Dynamics, vol. 27, no. 2, pp. 161-173, 2004.

[2] N. S. Khot, J. V. Zweber, D. E. Veley, H. Öz, and F. E. Eastep, "Flexible composite wing with internal actuation for roll manoeuvre," Journal of Aircraft, vol. 39, no. 4, pp. 521-527, 2002.

[3] J. M. Hall, "Executive summary AFTI/F-111 mission adaptive wing,” WRDC-TR 89-2083, 1989.

[4] E. Stanewsky, "Adaptive wing and flow control technology," Progress in Aerospace Sciences, vol. 37, no. 7, pp. 583-667, 2001.

[5] B. Sanders, F. E. Eastep, and E. Forster, "Aerodynamic and aeroelastic characteristics of wings with conformal control surfaces for morphing aircraft," Journal of Aircraft, vol. 40, no. 1, pp. 94-99, 2003.

[6] A. K. Jha and J. N. Kudva, "Morphing aircraft concepts, classifications, and challenges," in Industrial and Commercial Applications of Smart Structures Technologies, vol. 5388, pp. 213224, March 2004.

[7] C. O. Johnston, W. H. Mason, C. Han, and D. J. Inman, "Actuator-work concepts applied to unconventional aerodynamic control devices," Journal of Aircraft, vol. 44, no. 5, pp. 1459$1468,2007$.

[8] E. Stanewsky, "Aerodynamic benefits of adaptive wing technology," Aerospace Science and Technology, vol. 4, no. 7, pp. 439-452, 2000.

[9] M. R. Schultz and M. W. Hyer, "A morphing concept based on unsymmetric composite laminates and piezoceramic MFC actuators," in Proceedings of the 45th AIAA/ASME/ASCE/ AHS/ASC Structures, Structural Dynamics and Materials Conference, pp. 3192-3204, Palm Springs, Calif, April 2004.
[10] A. A. Paranjape, S. J. Chung, and M. S. Selig, "Flight mechanics of a tailless articulated wing aircraft," Bioinspiration and Biomimetics, vol. 6, no. 2, Article ID 026005, 2011.

[11] B. Obradovic and K. Subbarao, "Modeling of flight dynamics of morphing-wing aircraft," Journal of Aircraft, vol. 48, no. 2, pp. 391-402, 2011.

[12] A. Paranjape, S. Chung, H. Hilton, and A. Chakravarthy, "Dynamics and performance of a tailless MAV with flexible articulated wings," AIAA Journal, vol. 50, no. 5, 2012.

[13] B. Obradovic and K. Subbarao, "Modeling of dynamic loading of morphing-wing aircraft," Journal of Aircraft, vol. 48, no. 2, pp. 424-435, 2011.

[14] G. Gilyard, "In-flight transport performance optimization: an experimental flight research program and an operational scenario," NASA Technical Memorandum 206229, 1997.

[15] R. Henke and J. Mertens, "Adaptive technologies for future civil air transport," Air \& Space Europe, vol. 3, no. 3-4, pp. 80$82,2001$.

[16] P. Bourdin, A. Gatto, and M. I. Friswell, "Aircraft control via variable cant-angle winglets," Journal of Aircraft, vol. 45, no. 2, pp. 414-423, 2008.

[17] "Rolling moment derivative, $L_{\xi}$ for plain ailerons at subsonic speeds,"ESDU 88013, 1988.

[18] "Yawing moment coefficient for plain ailerons at subsonic speeds," ESDU 88029, 1988.

[19] R. B. Holloway, P. M. Burrisf, and R. P. Johannes, "Aircraft performance benefits from modern control systems technology," Journal of Aircraft, vol. 7, no. 6, pp. 550-553, 1970.

[20] I. Kroo, "Drag due to lift: concepts for prediction and reduction," Annual Review of Fluid Mechanics, vol. 33, pp. 587-617, 2001.

[21] H. P. Monner, D. Sachau, and E. Breitbach, Design Aspects of the Elastic Trailing Edge for an Adaptive Wing, Research and Technology Agency, Ottawa, Canada, 1999. 

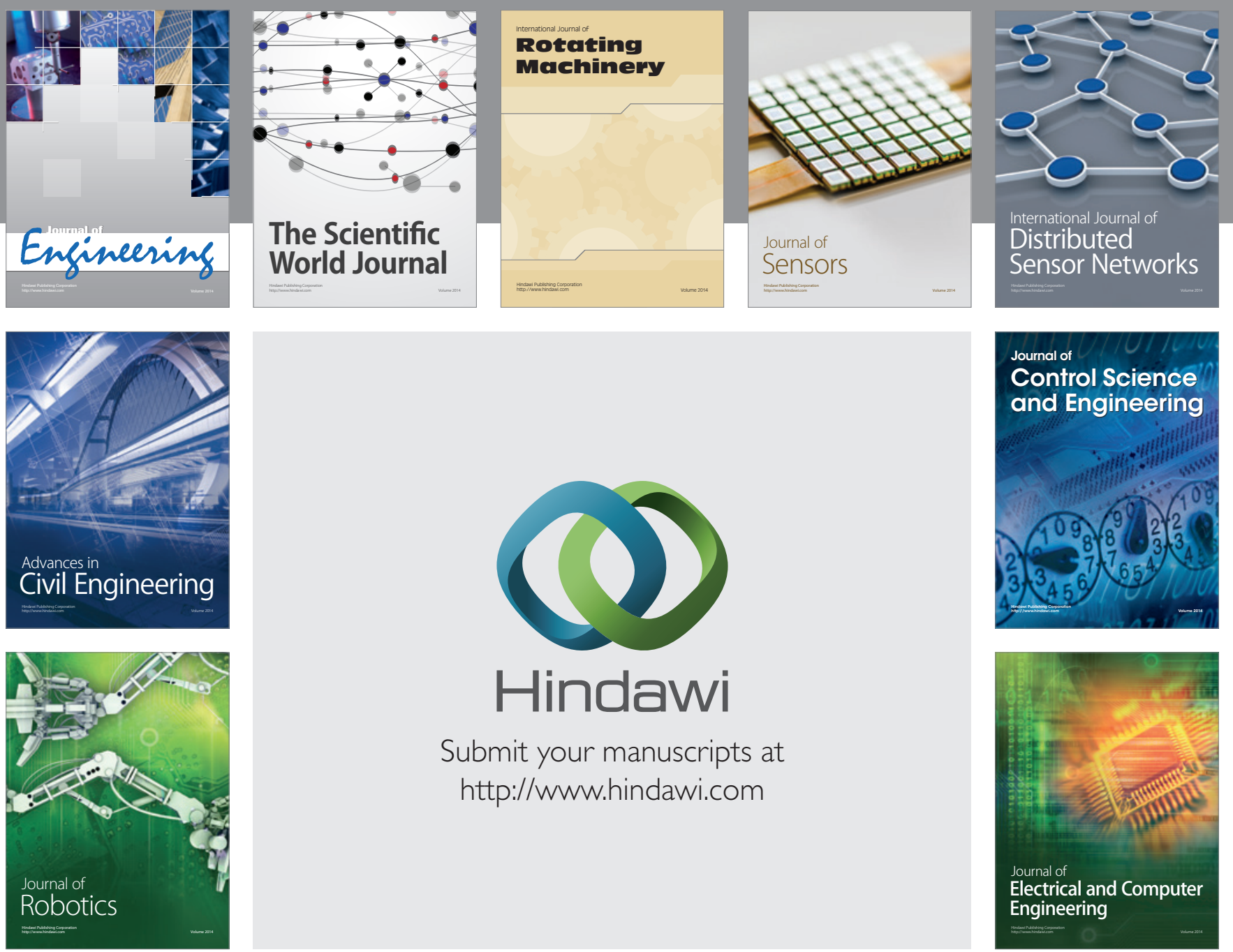

Submit your manuscripts at

http://www.hindawi.com
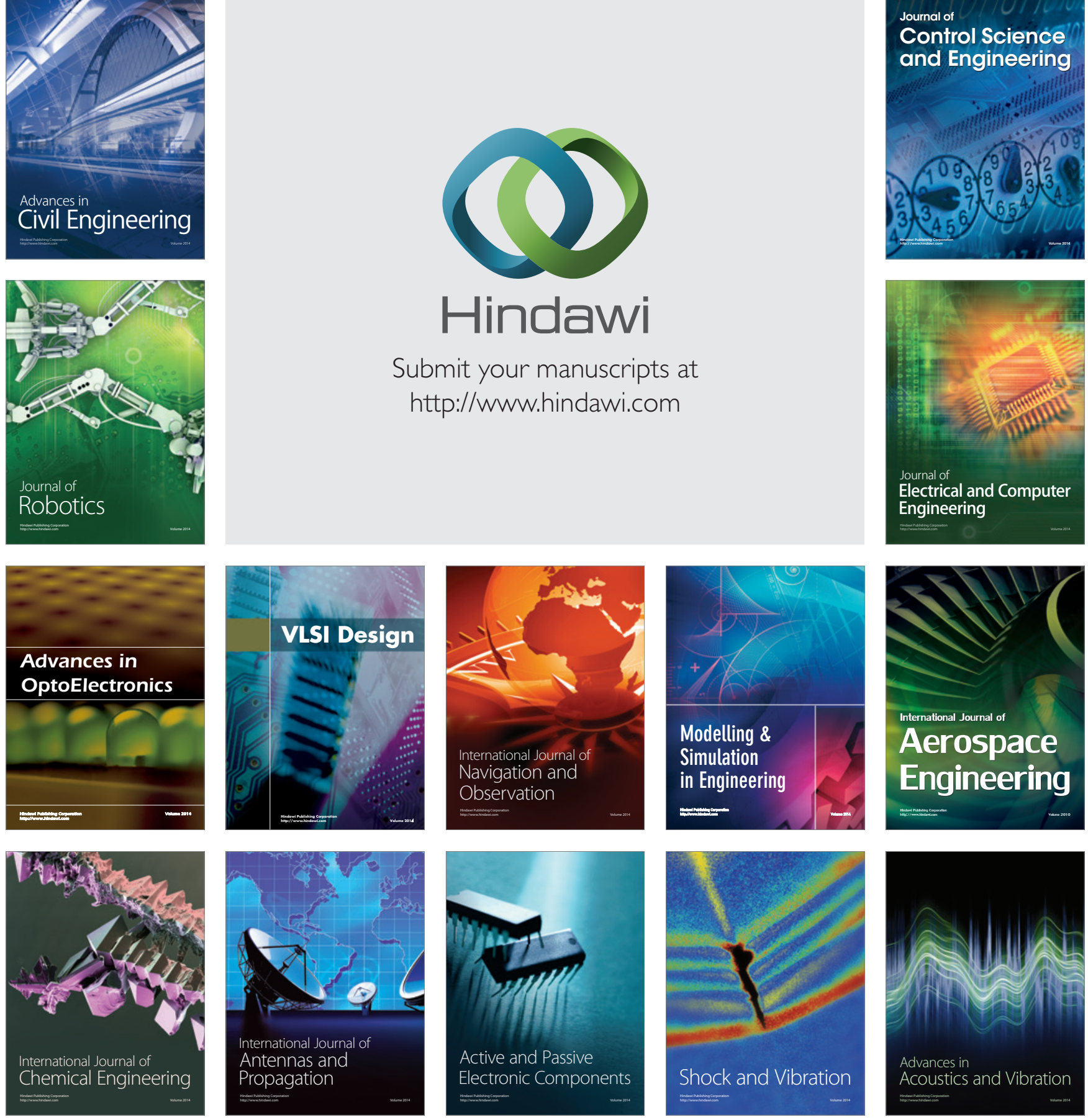